\title{
LARGE EDDY SIMULATION OF HIGHLY TURBULENT UNDER-EXPANDED HYDROGEN AND METHANE JETS FOR GASEOUS-FUELLED INTERNAL COMBUSTION ENGINES
}

\section{A. Hamzehloo and P.G. Aleiferis*}

Department of Mechanical Engineering, University College London, UK

*Author for Correspondence:

Dr. Pavlos Aleiferis

University College London

Department of Mechanical Engineering

Torrington Place, London WC1E 7JE, UK

Tel: +44-(0)20-76793862, Fax: +44-(0)20-73880180

E-mail: p.aleiferis@ucl.ac.uk

Full length article accepted for publication in the International Journal of Hydrogen Energy 


\begin{abstract}
Burning hydrogen in conventional internal combustion (IC) engines is associated with zero carbon-based tailpipe exhaust emissions. In order to obtain high volumetric efficiency and eliminate abnormal combustion modes such as preignition and backfire, in-cylinder direct injection (DI) of hydrogen is considered preferable for a future generation of hydrogen IC engines. However, hydrogen's low density requires high injection pressures for fast hydrogen penetration and sufficient in-cylinder mixing. Such pressures lead to chocked flow conditions during the injection process which result in the formation of turbulent under-expanded hydrogen jets. In this context, fundamental understanding of the under-expansion process and turbulent mixing just after the nozzle exit is necessary for the successful design of an efficient hydrogen injection system and associated injection strategies. The current study used large-eddy simulation (LES) to investigate the characteristics of hydrogen under-expanded jets with different nozzle pressure ratios (NPR), namely 8.5, 10,30 and 70. A test case of methane injection with $\mathrm{NPR}=8.5$ was also simulated for direct comparison with the hydrogen jetting under the same NPR. The near-nozzle shock structure, the geometry of the Mach disk and reflected shock angle, as well as the turbulent shear layer were all captured in very good agreement with data available in the literature. Direct comparison between hydrogen and methane fuelling showed that the ratio of the specific heats had a noticeable effect on the near-nozzle shock structure and dimensions of the Mach disk. It was observed that with methane, mixing did not occur before the Mach disk, whereas with hydrogen high levels of momentum exchange and mixing appeared at the boundary of the jet. This was believed to be the effect of the high turbulence fluctuations at the nozzle exit of the hydrogen jet which triggered Gortler vortices. Generally, the primary mixing was observed to occur after the location of the Mach disk and particularly close to the jet boundaries where large-scale turbulence played a dominant role. It was also found that NPR had significant effect on the mixture's local fuel richness. Finally, it was noted that applying higher injection pressure did not essentially increase the penetration length of the hydrogen jets and that there could be an optimum NPR that would introduce more enhanced mixing whilst delivering sufficient fuel in less time. Such an optimum NPR could be in the region of 100 based on the geometry and observations of the current study.
\end{abstract}




\section{INTRODUCTION}

\subsection{Hydrogen-Fuelled Internal Combustion Engines}

In order to tackle issues related to the ever increasing cost of conventional fuels and carbon emissions, it is necessary to diversify towards cleaner and more sustainable fuels. Accordingly, several liquids and gases have been proposed as alternative fuels for internal combustion (IC) engines; among them, gaseous hydrogen $\left(\mathrm{H}_{2}\right)$ can offer a promising long-term solution. The concept of a hydrogen economy has been proposed since the mid-1970s [1, 2]. Several experimental and computational studies have been conducted on the development of hydrogen-fuelled IC engines in the past 15 years [3-22]. Port fuel injection (PFI) [6-12] and in-cylinder Direct Injection (DI) [13-22] of hydrogen are the two typical options for hydrogen-fuelled IC engines. DI offers higher volumetric efficiency and eliminates abnormal combustion modes such as preignition and backfire. These attributes, in conjunction with the flexibility in possible injection strategies, make DI preferable for hydrogen IC engines. However, hydrogen's low density requires high injection pressures in order to achieve fast fuel delivery and optimise mixture formation. Such pressures lead to turbulent under-expanded hydrogen jets past the nozzle exit $[18,22]$. Therefore, fundamental understanding of the under-expansion process and turbulent mixing just after the nozzle exit is necessary for the design of an efficient hydrogen injection system and associated injection strategies for enhanced engine performance.

\subsection{Under-Expanded Jets}

\subsubsection{Definition}

The ratio of the nozzle total pressure $\left(P_{0}\right)$ to the ambient (in-cylinder) static pressure $\left(P_{\infty}\right)$, namely the nozzle pressure ratio (NPR), has a significant effect on the characteristics of a gaseous jet issuing from a circular nozzle. Based on the level of NPR, jets can be classified as subsonic, moderately under-expanded and highly under-expanded [23-25]. Specifically, Donaldson and Snedeker [25] categorized the gaseous jets into three major types based on the NPR $\left(P_{0} / P_{\infty}\right)$ and under-expansion ratio $\left(P_{1} / P_{\infty}\right)$ as subsonic $\left(1>P_{\infty} / P_{0}>0.528\right.$, $\left.P_{1} / P_{\infty}=1\right)$, moderately under-expanded $\left(0.48>P_{\infty} / P_{0} \geq 0.26,1.1<P_{1} / P_{\infty} \leq 2\right)$ and highly under-expanded $\left(0.26 \geq P_{\infty} / P_{0} \geq 0,2 \leq P_{1} / P_{\infty} \leq \infty\right)$. For NPR above $\sim 4$ the jet is considered to be highly under-expanded. As illustrated in Figure 1, at such condition, infinite number of Mach waves, namely the Prandtl-Meyer expansion fan, form at the nozzle lip that spread out to the jet boundary and reflect as weak compression waves which form the intercepting oblique shock that is ended by a slightly curved strong normal shock socalled Mach disk [23]. The intercepting shock and the Mach disk form the first shock cell that is labelled "barrel shape shock" since it has a cylindrical shape. On a 2-D plane a reflected shock and a slip line is seen at the "triple point" which is the merging location of the intercepting shock and the Mach disk (see Figure 1). The flow behind the Mach disk is subsonic, whilst the flow behind the reflected shock is still supersonic [23-25]. For higher degrees of under-expansion, e.g. NPR $\approx 8$, the subsonic core behind the Mach disk rapidly accelerates and becomes supersonic once more, which then shapes a second shock cell that may resemble the first shock cell and even include a normal shock comparable to the Mach disk [25]. At 
extremely high levels of NPR, a very large Mach disk forms at the nozzle exit, with no additional normal shocks downstream, and the jet then decays resembling a subsonic jet [25].

\subsubsection{Near-nozzle Sonic Characteristics}

The near-nozzle sonic characteristics of under-expanded jets are quantified by several important parameters that include the dimensions of the Mach disk, angle of reflected shock at the triple point and length of the shear layer thickness (maximum distance between the slip line and reflected shock). These, not only provide important information regarding the upstream condition and effective injection pressure, but also have significant effect on the annular shear layer thickness and consequently on the mixing characteristics of the under-expanded jet. These parameters can also be used as fundamental measures for comparing underexpanded jets with different values of NPR and also for validating numerical models of these types of jets.

The Mach disk's dimensions are typically characterised by the axial distance of the disk from the nozzle exit, i.e. the Mach disk height $\left(H_{\text {disk }}\right)$, and the distance between the two triple points (see Figure 1) i.e. the Mach disk width $\left(W_{\text {disk }}\right)$. The reflected shock angle and shear layer thickness are significantly affected by the Mach disk dimensions and although there is still not a universal relation available for these two parameters, several correlations have been suggested for predicting $H_{\text {disk }}$ and $W_{\text {disk }}$.

By conducting experimental investigations and with the assumption of choked condition at the nozzle exit $(M a=1)$, Crist et al. [23] suggested that the relation between NPR and the Mach disk height can be given by:

$$
\frac{H_{\text {disk }}}{D} \approx \frac{1}{\sqrt{2.4}} \times \sqrt{\frac{P_{0}}{P_{\infty}}}
$$

By assuming a large Mach number at the location of the Mach disk $\left(M a_{\text {disk }}>>1\right)$ and by combining equation

(1) with some isentropic relations, Crist et al. [23] also derived a correlation which relates $H_{d i s k}$ to $M a_{d i s k}$ and the ratio of specific heats $(\gamma)$ as follows:

$$
\frac{H_{\text {disk }}}{D} \sim M a_{\text {disk }}{ }^{1 /(\gamma-1)}\left[\frac{\gamma+1}{4.8 \gamma}\left(\frac{\gamma-1}{2}\right)^{\gamma / \gamma-1}\right]^{1 / 2}
$$

Ewan and Moodie [26] and Antsupov [27] separately suggested the following correlations in order to predict $H_{\text {disk }}$ and $W_{\text {disk: }}$ :

$$
\begin{gathered}
H_{\text {disk }}=0.77 \times D+0.068 \times D^{1.35}\left(\frac{P_{1}}{P_{\infty}}\right) \\
\frac{W_{\text {disk }}}{D}=\log \left(\frac{P_{1}}{P_{\infty}}\right)^{5 / 2}-\frac{3}{4}
\end{gathered}
$$

where $P_{1}$ is the static pressure at the nozzle exit. Velikorodny and Kudriakov [28] reported that by using theoretical analysis based on dimensional groups the following relations can be derived for the Mach disk:

$$
\frac{H_{\text {disk }}}{D}=\frac{1}{2} \sqrt{\gamma} \sqrt{\frac{P_{1}}{P_{\infty}}}\left(\frac{\gamma+1}{\gamma-1}\right)^{1 / 4}
$$




$$
\frac{W_{\text {disk }}}{D}=\zeta \frac{H_{\text {disk }}}{D} \sqrt{1-\frac{\gamma+1}{\gamma}\left(\frac{\gamma+1}{\gamma-1}\right)^{-1 / 2}}
$$

where $\zeta$ is an empirical constant that accounts for the growth of the mixing layer. A commonly used experimental correlation for the Mach disk height was proposed by Ashkenas and Sherman [29] as follows:

$$
\frac{H_{\text {disk }}}{D}=0.67 \sqrt{\frac{P_{0}}{P_{\infty}}}
$$

\subsubsection{Mixing Characteristics}

The jet tip penetration $\left(\mathrm{Z}_{\mathrm{tip}}\right)$ and its volumetric growth $\left(V_{j e t}\right)$ are two key properties of under-expanded gaseous fuel jets when it comes to air/fuel mixing. They have direct effects on the mechanism of mixture preparation and degree of fuel stratification and can influence in return the combustion quality and tailpipe emissions level.

The tip penetration of under-expanded jets has been subject to many theoretical studies. Turner [30] was the first to develop a mathematical model for the under-expanded gaseous jets. The model approximates the geometry of a gaseous jet as a spherical head vortex and a quasi-steady jet region that conveys the momentum; momentum is constantly supplied thorough the nozzle orifice and is passed between the quasisteady region and the head vortex. Hill and Ouellette [31] employed Turner's model to develop an analytical relationship for the tip penetration as follows:

$$
\mathrm{Z}_{t i p}=\Gamma\left(\frac{M}{\rho_{\infty}}\right)^{1 / 4} t^{1 / 2}
$$

where $M$ is the momentum flow rate supplied by the nozzle and $\Gamma$ is a scaling constant related to the entrainment level (normally has a value of $\sim 3$ for jets issued from round nozzles). As dictated by equation (8) and also as formulated by Abraham [32], the jet penetration under conditions similar to those prevailing in DI engines (under-expanded with Reynolds number in order of $10^{5}$ ) obeys a linear dependency on the square root of time. However, experiments have shown that this linear relation is achieved after an initial non-linear transient behaviour [33].

\subsection{Literature Survey}

Experimental studies of the near-nozzle shock structure and mixing characteristics of under-expanded jets have been conducted by several researchers using wind tunnel facilities, Schlieren and shadowgraph photography, Rayleigh scattering, Laser Doppler Anemometry (LDA) and Planar Laser-Induced Fluorescence (PLIF) in order to measure the mixing parameters and visualise the near-field shock structure of under-expanded air/nitrogen jets [23, 25, 26, 29, 34-37]. Computational studies of under-expanded jets have been performed using compressible Euler equations [38-41], Reynolds Averaged Navier-Stokes (RANS) and Large Eddy Simulation (LES) methodologies [41-52], mainly for air jets or by assuming the injection of a passive scalar. Early studies were also conducted by analytical approaches and the method of characteristics $[24,53]$. Prudhomme and Haj-Hariri [38] examined moderate and highly under-expanded jets 
by solving the axisymmetric Euler equations with a finite element solver and Roe's approximate method [54]. Their implicit computational framework was able to predict the location of the Mach disk and the wave structure inside the jet. However, in order to study the mixing characteristics of under-expanded jets by including molecular diffusion effects (that can be significant with hydrogen fuelling), use of the NavierStokes equations is necessary rather than Euler's equations. RANS simulations are low in cost and have been proven accurate at capturing the shock structure of under-expanded jets [42-46], but their ability to predict the mixing of highly turbulent jets remains unclear as results can be quite sensitive to the choice of turbulence model. Therefore, LES is considered more suitable for modelling the details of highly turbulent under-expanded jets and the following sub-section presents a brief review of relevant studies.

\subsubsection{LES Modelling}

For simulations of under-expanded jets for aerospace applications where massive attached faces (e.g. nozzle inner wall) and complex shear flows exist with strong compressibility at high temperatures, Detached Eddy Simulation (DES) has been suggested. DES is based on a hybrid RANS/LES methodology where RANS is employed at regions close to walls (attached) and LES for the remaining volume of the domain. This is a more feasible option to LES since the latter requires considerably finer grid close to the walls [47, 48]. However, for conditions relevant to injectors of gaseous-fuelled engines, it has been shown [49-51] that if the injector body has been included in the computational domain by assigning a slip wall condition LES can be used with good level of accuracy (more details discussed later in the current paper). For example, Dauptain et al. $[49,50]$ used Smagorinsky LES on an unstructured tetrahedral grid with an explicit thirdorder solver that featured a centred shock capturing algorithm to study free and impinging under-expanded jets. Different number of cells were investigated by these authors and it was found that a grid with $D / 20$ cell size close to the nozzle exit could provide grid independency of the results. Recently Vourinen et al. [51] modelled the injection of a passive scalar with NPR in range of 4.5-8.5 using an implicit LES (ILES) technique. The near-nozzle shock structure and the strong compression effects were taken into account by using a bulk viscosity model in conjunction with a second-order filter that was activated at the location of the strong shocks. Vourinen et al. [51] also showed that the Mach disk dimensions and shock structure were in very good agreement with the experimental observations of $\mathrm{Yu}$ et al. [37, 52] that included PLIF visualisation. Important mixing characteristics, e.g. jet tip penetration and jet volumetric growth of a passive scalar with nitrogen properties for $\mathrm{NPR} \leq 8.5$ were also investigated by Vourinen et al. [51] and a new scaling parameter for the volumetric growth of under-expanded jets was proposed.

\subsubsection{Numerical Modelling of Hydrogen Under-Expanded Jets}

Most previous studies on under-expanded jets have considered large diameter nozzles with air/nitrogen as working gas. There are very limited data in the literature on under-expanded hydrogen jets (or other light gases such as helium), especially for nozzles with diameters relevant to IC engine injectors. Velikorodny and Kurdriakov [28] studied computationally under-expanded air and helium jets issued from a circular nozzle with $D=1 \mathrm{~mm}$ and NPR=30. The numerical methodology employed the Advection Upstream Splitting Method (AUSM+) [55] for the convective fluxes and direct solution of the governing equations without SubGrid Scale (SGS) turbulence models. It was found that the near-field shock structure of the helium jet 
required more time than the air jet to reach quasi-steady conditions. Ruggles and Ekoto [56] used Schlieren photography to visualise the near nozzle shock structure and Planar Laser Rayleigh Scatter imaging in order to measure the instantaneous mole fraction downstream of the Mach disk in an under-expanded hydrogen jet issued from a nozzle with diameter $D=1.5 \mathrm{~mm}$ and with NPR=10. The Mach disk, the reflected shocks and the oblique shock trains after the Mach disk were clearly captured by the visualisation technique. Ruggles and Ekoto [56] noticed that air and hydrogen may have mixed within the slip region and bypassed the Mach disk, therefore, notional nozzle theories that assumed that all gas passed the Mach disk were not accurate enough. It was suggested that more experimental and computational works were required in order to clarify the hydrogen-air mixing behaviour very close to the nozzle exit. Gorle et al. [57] and Gorle and Iaccarino [58] conducted experimental (Schlieren) and computational (RANS and LES) studies of under-expanded hydrogen jets from a nozzle with diameter $D=2 \mathrm{~mm}$ and NPR=30. It was noticed that both RANS and LES were able to capture the near nozzle shock structure of under-expanded hydrogen jets in good agreement with experiments. Khaksarfard et al. [59] investigated numerically the release of high pressure hydrogen (10-70 MPa) into ambient through a hole with diameter $D=5 \mathrm{~mm}$. The Able-Noble real gas Equation of State (EoS) was used by the latter authors and it was found that for very high injection pressures the ideal gas equation underestimated the release velocity; e.g. for injection pressure of $70 \mathrm{MPa}$ the velocity was underestimated by $20 \%$. They concluded that for injection pressures above $10 \mathrm{MPa}$ a real gas equation must be used in order to obtain accurate results. Recently Bonelli et al. [60] used $k$ - $\varepsilon$ RANS modelling with a special correction in the dissipation terms (to account for the so called 'round-jet anomaly') in conjunction with three different EoS, namely ideal gas, van der Waals, and Redlich-Kwong. They studied high pressure injection of hydrogen $\left(P_{0}=75 \mathrm{MPa}, T_{0}=300 \mathrm{~K}\right)$ into still nitrogen $\left(P_{\infty}=5 \mathrm{MPa}, T_{\infty}=300 \mathrm{~K}\right)$ through a nozzle with inner and outer diameters of $0.3 \mathrm{~mm}$ and $0.6 \mathrm{~mm}$, respectively. These authors noticed that the van der Waals and Redlich-Kwong EoS predicted lower mass flow rate of hydrogen by $10 \%$ and $8.7 \%$, respectively, than the ideal gas EoS. It was also found that at very high injection pressures $\left(P_{\mathrm{o}}>>10 \mathrm{MPa}\right)$ the ideal gas underestimated the Mach disk height and overestimated the Mach disk width in comparison to real gas EoS [60].

\subsection{Present Contribution}

Very little computational studies have been conducted on under-expanded hydrogen jets particularly with respect to conditions of DI for hydrogen-fuelled IC engines. Previous computational work by the current authors [22] partially focused on RANS and LES of under-expanded hydrogen jets where a stepped-shape nozzle was investigated using a moderately-fine grid size. The current study aimed to investigate further the near-nozzle shock structure and mixing characteristics of highly turbulent under-expanded hydrogen jets by:

- Conducting LES on a very fine unstructured hexahedral grid and making direct comparisons between hydrogen and methane gas injection.

- Studying the effect of increasing NPR on the under-expansion and mixing characteristics of hydrogen jets.

- Investigating the transient flow development upstream of the nozzle exit, i.e. inside the nozzle volume of high-pressure gaseous injectors. 
- Obtaining a set of reference values for the near nozzle shock structure, namely the Mach disk height and width, the reflected shock angle, the shear layer thickness and the length of the first subsonic core.

- Quantifying and comparing the jet penetration length and volumetric growth for hydrogen and methane fuelling.

- Studying the effect of hydrogen's high diffusivity and low density on the sonic and mixing characteristics.

\section{COMPUTATIONAL METHODOLOGY}

\subsection{Numerical Formulation}

The viscous flow of a Newtonian multi-component compressible fluid of $\boldsymbol{N}$ species $\left(Y_{1}, Y_{2}, Y_{3}, \ldots Y_{i}, \ldots, Y_{N}\right)$ is governed by the Navier-Stokes equations and species transport equations [61, 62]. For $N$ species, $N-1$ transport equations are solved; the mass fraction of the $N^{\text {th }}$ component is determined by the restriction that the total mass fraction must be unity. Pressure is coupled to density and temperature by the ideal gas EoS. The STAR-CCM+ code was used for the solution of the governing equations within the objectives of the current work. The code benefits from a coupled finite volume method that discretises and solves the governing equations simultaneously using an implicit time marching approach. To provide efficient solution a preconditioning matrix is integrated into the set of equations that consequently requires viscous and inviscid fluxes to be defined [61]. In the present study in order to express the inviscid fluxes, the $\mathrm{AUSM}^{+}$ scheme was applied because it is believed to be accurate and robust in solving fluid flows that contain discontinuity such as shock waves [55]. $\mathrm{AUSM}^{+}$uses a separate splitting for the pressure terms and also avoids an explicit artificial dissipation. $\mathrm{AUSM}^{+}$discretises the fluxes directly as follows:

$$
\mathbf{f}_{f}=\mathbf{m}_{\mathbf{i}}^{+}(1, u, v, \ldots, H)_{\mathrm{o}}^{\mathrm{T}}+\mathbf{m}_{\mathbf{i}}^{-}(1, u, v, \ldots, H)_{1}^{\mathrm{T}}+\mathbf{P}_{i}
$$

where $\mathbf{m}_{\mathbf{i}}$ is the mass flux across a cell interface, $\mathbf{m}_{\mathbf{i}}^{+}$is defined as $\left(\mathbf{m}_{\mathbf{i}}+\left|\mathbf{m}_{\mathbf{i}}\right|\right) / 2, \mathbf{m}_{\mathbf{i}}{ }^{-}$is defined as $\left(\mathbf{m}_{\mathbf{i}}-\left|\mathbf{m}_{\mathbf{i}}\right|\right) / 2$, and $\mathbf{P}_{i}$ is the pressure flux. The mass flux and pressure flux are calculated on the basis of local flow characteristics to ensure precise information propagation inside the fluid for convective and acoustic processes. The viscous fluxes can be written in terms of the stress tensor $\mathbf{T}$ which is defined using Boussinesq's approximation as [61]:

$$
\begin{gathered}
\mathbf{T}=\mathbf{T}_{\text {laminar }}+\mathbf{T}_{\text {turbulent }} \\
\mathbf{T}=\left(\mu+\mu_{t}\right)\left[\nabla \mathbf{V}+\nabla \mathbf{V}^{\mathbf{T}}-\frac{2}{3}(\nabla \cdot \mathbf{V}) \mathbf{I}\right]
\end{gathered}
$$

With LES the governing equations are filtered in such a way that the turbulence scales greater than the grid resolution are solved directly and the smaller scales are modelled using SGS models that define the turbulent viscosity $\mu_{t}$ that is used in equation (11) to calculate the turbulent stress tensor:

$$
\mathbf{T}_{\text {Turbulent }}=2 \mu_{t} \mathbf{S} \frac{2}{3}\left(\mu_{t} \nabla \cdot \mathbf{V}+\rho k\right) \mathbf{I}
$$

where $\mathbf{S}$ is the strain rate tensor computed from the resolved velocity field as:

$$
\mathbf{S}=\frac{1}{2}\left(\nabla \mathbf{V}+\nabla \mathbf{V}^{\mathrm{T}}\right)
$$


Wall-Adapting Local-Eddy Viscosity (WALE) sub-grid scale modelling [63] was applied and $\mu_{t}$ was approximated by:

$$
\mu_{t}=\rho \Delta^{2} S_{w}
$$

where $\Delta$ is the length scale or grid filter width and $S_{w}$ is the deformation parameter that is a function of the strain rate tensor [63]. It should be noted that the current computational framework was second-order accurate for both temporal and spatial discretization.

The molecular diffusivity was defined as the binary diffusivity of an air-hydrogen (or air-methane) system and was calculated using the Chapman-Enskong theory for gaseous diffusion coefficients as follows [64]:

$$
D_{i}=\frac{1.86 \times 10^{-3} T^{3 / 2}\left(1 / M_{1}+1 / M_{2}\right)^{1 / 2}}{P_{a t m} \sigma_{12}^{2} \Omega}
$$

where $D_{i}$ is the coefficient of molecular diffusivity, $T$ is the absolute temperature in $\mathrm{K}, P_{a t m}$ is the pressure in atm, $M_{1}$ and $M_{2}$ are the molecular weights, and $D_{i}$ is in $\mathrm{cm}^{2} / \mathrm{s}$. The quantities $\sigma_{12}$ and $\Omega$ are molecular properties; $\sigma_{12}$ is the collision diameter, given in angstroms, which is the arithmetic average of the two species [64]:

$$
\sigma_{12}=0.5\left(\sigma_{1}+\sigma_{2}\right)
$$

Values of $\sigma_{1}$ and $\sigma_{2}$ can be found in [65]. The values of the dimensionless quantity $\Omega$ depend on an integration of the interaction between the two species which can be described by the Lennard-Jones 12-6 potential and is usually of order unity $[64,65]$.

\subsection{Simulation Setup}

The simulations were performed by considering a system that consisted of a high pressure hydrogen tank and a low pressure air-containing chamber that were linked by a converging nozzle with exit diameter $D=1.5$ $\mathrm{mm}$, as shown in Figure 2. Overall five simulations were carried out: four were based on hydrogen injection with four different values of NPR, namely $8.5,10,30,70$, and one simulation of methane injection with $\mathrm{NPR}=8.5$. The low-pressure chamber was kept for all simulations at $98.37 \mathrm{kPa}$, whereas the temperature of both the high pressure tank and the low pressure chamber was kept at $295.4 \mathrm{~K}$ and $296 \mathrm{~K}$, respectively. The top boundary of the high pressure tank was considered a stagnation inlet in order to maintain the injection pressure, while the side and the bottom boundaries of the low pressure air-containing chamber were set to pressure outlet.

The mechanics of flow in small size devices may differ from those in large scale machines. Therefore, as categorized by Gad-el-Hak [66], various configurations of the governing equations and boundary conditions should be applied depending on the regime of the Knudsen number $(K n)$ :

$$
K n=\frac{l}{L}=\sqrt{\frac{\pi \gamma}{2}} \frac{M a}{R e}
$$

where $l$ is the mean free path of gas molecules, $L$ is a characteristic length and the Reynolds number Re can be defined as $R e=U L / v$. For laminar boundary layer flows through tiny ducts, Gad-el-Hak [66] showed that, since $\delta / L \sim 1 / \sqrt{R e}$ (where $\delta$ is the boundary layer thickness), the Knudsen number is directly related to the Mach number and inversely related to the square root of the Reynolds number and can be written as: 


$$
K n \sim \frac{M a}{\sqrt{R e}}
$$

Since for turbulent flows it is possible to write $\delta / L \sim 1 /(R e)^{0.2}$, it can be concluded that according to (18) $K n \sim M a /(R e)^{0.2}$. In the current study Re inside the nozzle volume ranged from $10^{5}$ to $10^{6}$, therefore $K n$ number was of the order of $10^{-2}-10^{-1}$. According to [66] if $10^{-3} \leq K n \leq 10^{-1}$ then slip boundary conditions should be used on the walls. A slip boundary with adiabatic condition has been applied in previous studies of different researchers [49-51], hence the nozzle boundary was set to adiabatic slip in the current work. In order to avoid the formation of any artificial boundary layers and to eliminate the need of considerably finer grid, the wall boundaries of the high pressure hydrogen tank were also considered to be of adiabatic slip type [49-51].

An unstructured hexahedral grid was created by means of the trimmer facility of STAR-CCM+ that produces cubic cells with identical size in all directions. As it can be seen in Figure 2, a conical refined area was implemented within the computational grid that covered the nozzle volume and a length of $20 D$ downstream of the nozzle exit. The use of such refinement was necessary to capture the flow details inside the nozzle, the shock structure very close to the nozzle exit and the mixing process downstream of the nozzle. The refined area very close to the nozzle exit (within a distance of $\sim 6.7 D$ ) and inside the nozzle volume had a cell size of $\sim 0.03 \mathrm{~mm}(D / 50)$, whereas further downstream it had a cell size of $\sim 0.06 \mathrm{~mm}$. The cell size expanded from the refined area towards the largest cell size inside the rest of the domain $(1.0 \mathrm{~mm})$ through a four level grid expansion. A total of $\sim 13.5$ million cells occupied the computational domain. The grid resolution used in the current study was selected to be as dense as possible according to computational data on under-expanded jets available in the literature $[44,45,55,58]$ and also based on the computational power available to the authors. Coarser grids (with $D / 40$ and $D / 30$ uniform cell sizing) were also examined and the current grid was found to be able to capture near-nozzle sonic characteristics in very good agreement with experimental data (as will be discussed later). Moreover, it should be noted that the grid used in the current work had uniform cell size within the refinement areas (unlike most studies available in the literature) in order to eliminate problems that may occur due to the LES filtering process on non-uniform grids.

The simulations started from a rest condition where it was assumed that hydrogen occupied the entire high pressure tank and a small part of the converging nozzle volume up to $\sim 1.4 D$ upstream the nozzle exit. Air occupied the low pressure chamber and remaining of the nozzle volume. The length of the high pressure hydrogen tank was believed to be long enough (40D) so that the flow could be considered to be almost at rest at the stagnation inlet within the injection duration. This assumption eliminated the need for applying any initial perturbation at the inlet boundary for LES studies.

The molecular diffusivity was calculated using equation (23) and values of $D_{i} \approx 7.94 \times 10^{-5} \mathrm{~m}^{2} / \mathrm{s}$ and $D_{\mathrm{i}} \approx 2.1 \times 10^{-5} \mathrm{~m}^{2} / \mathrm{s}$ were obtained for air-hydrogen and air-methane systems, respectively. The dynamic viscosity $(\mu)$ in equation (11) was calculated using Sutherland's law as follows:

$$
\mu=\mu_{s} \frac{T_{s}+C_{s}}{T+C_{s}}\left(\frac{T}{T_{s}}\right)^{3 / 2}
$$


where $\mu_{s}$ and $T_{s}$ are reference viscosity and reference temperature values, respectively, and $C_{s}$ is the Sutherland's constant; those values have been tabulated in table 1 for air, hydrogen and methane. For the mixture viscosity, either mass-weighted mixing or volume-weighted mixing methods can be used. Both methods were examined and similar results achieved. However, since for non-ideal gas mixtures a volumeweighted approach is suggested as good practice by the code developers, a volume-weighted mixing methodology was finally selected in the current work to allow direct comparison between the ideal gas results obtained here and non-ideal gas studies to be conducted in the future.

Due to the high velocity in the near-field of the under-expanded jets, the integral time scale of the flow could be defined as $t_{0}=D / 2 U_{1}$ [51]. Assuming chocked condition at the nozzle exit ( $\left.M a=1\right), U_{1}$ would be that of the speed of sound which, with the ideal gas assumption, was calculated as:

$$
U_{1}=a=\sqrt{\gamma R T_{1}}
$$

where the temperature at the nozzle exit $\left(T_{1}\right)$ was defined as [53]:

$$
T_{1}=\frac{T_{0}}{1+\frac{\gamma-1}{2} M a^{2}}
$$

Using equations (20) and (21) with $M a=1$ at the nozzle exit, the nominal integral time scale for hydrogen $(\gamma \approx 1.41, R \approx 4,124 \mathrm{~J} / \mathrm{kgK})$ and methane $(\gamma \approx 1.32, R \approx 518 \mathrm{~J} / \mathrm{kgK})$ jets was calculated to be $t_{0} \approx 6.2 \times 10^{-7} \mathrm{~s}$ and $t_{0} \approx 1.8 \times 10^{-6} \mathrm{~s}$, respectively. A time-step of $5.0 \times 10^{-9} \mathrm{~s}$ was used at the beginning of the simulations to build up the initial pressure gradient inside the nozzle volume smoothly, which was then increased to $5.0 \times 10^{-8} \mathrm{~s}$ and $1.0 \times 10^{-7} \mathrm{~s}$ (for the rest of the simulation time) for hydrogen and methane, respectively. These values were almost 10 times smaller than the nominal integral time scale of the flows and were considered adequate to capture the turbulent temporal fluctuations within feasible CPU times. A comparison between the settings of the current work and those of a selection of previous numerical studies of underexpanded jets is presented in Table 2 for direct comparison and completeness.

\section{RESULTS AND DISCUSSION}

\subsection{Model Validation}

The current computational framework was validated against two experimental and numerical test cases available in the literature. First a computational test case was set up based on the experimental work of Ruggles and Ekoto [56]; in this model, hydrogen was injected with NPR=10 using the converging nozzle configuration shown earlier in Figure 2. Figure 3 compares the current LES results with the mean Schlieren images of Ruggles and Ekoto [56]. The LES image in Figure 3 was produced by time-averaging the magnitude of the density gradient $(|\nabla \rho|)$ in $\sim 1.6 t_{0}$ intervals (50 samples) starting from $t \approx 403 t_{0}$. A grey scale legend was used in order to offer better visualisation of the near-field shock structures. It is clear that the Mach disk height and width, as well as the reflected shock angle, were predicted in very close agreement with the Schlieren visualisation. Specifically, according to Ruggles and Ekoto [56] the Mach disk height and width were $H_{\text {disk }}=3.05 \mathrm{~mm}$ and $W_{\text {disk }}=1.30 \mathrm{~mm}$, respectively, whereas the current LES study predicted higher values by just $1.3 \%$ and $3.0 \%$, i.e. $H_{d i s k}=3.09 \mathrm{~mm}$ and $W_{\text {disk }}=1.34 \mathrm{~mm}$, respectively. Similarly to the 
experiments of [56], the current LES study showed that the reflected shock (at the triple point) was inclined at $\sim 28^{\circ}$ to the nozzle axis; the slip lines were also predicted in good agreement with the experiments. LES also showed that hydrogen and air are mixing outside the boundaries of the barrel-shape shock which means that not all the hydrogen passed through the Mach disk; this confirmed the observations of [56].

Figure 4 compares the time-averaged and instantaneous (at $t \approx 484 t_{0}$ ) values of $|\nabla \rho|$ predicted by LES against the Root Mean Square (RMS) Schlieren image of the hydrogen jet of Ruggles and Ekoto [56]. The RMS image was specifically selected in order to highlight the flow gradient and mixing layers of the Schlieren visualisation, therefore, the time-averaged data of the density gradient (LES) can be safely compared against it. The jet width was predicted in satisfactory agreement with the experiments, albeit slightly narrower by about $2-3 \%$ than in the Schlieren image. This can be considered an effect of higher level of turbulence at the nozzle exit in the experimental work than in the LES study, e.g. due to the nozzle surface roughness, back pressure fluctuation, etc. The instantaneous snapshot of the density gradient in Figure 4 shows a noticeable level of momentum exchange at the jet boundary before the Mach disk which represents the previously mentioned hydrogen-air mixing. In Figure 4, the red dashed lines separate two regions with different brightness in the RMS Schlieren image. This brightness difference was noted by Ruggles and Ekoto [56] where variations in mixture fraction and/or changes in pressure and temperature were suggested as the possible reasons for this to occur. The current LES study verified that the region between the dashed lines in fact had a considerable density gradient that can be interpreted as a high degree of hydrogen-air mixing. This mixing region was slightly wider in LES than shown by the experiment.

Two more LES test cases of methane and hydrogen, using NPR=8.5, were also set up and run in order to make an informed analysis against the LES work of Vuorinen et al. [51] (see Table 2 for further specifications). Although the type of gas, nozzle diameter and configuration used in the current study were different from those of [51], using the same NPR of 8.5 provided the opportunity to perform direct comparison of the near-nozzle shock structure characteristics. Vuorinen et al. [51] reported that the Mach disk height of their under-expanded nitrogen jet was $H_{d i s k}=1.84 \mathrm{D}$, whereas in the current study a Mach disk height of $H_{\text {disk }}=1.85 \mathrm{D}$ and $H_{\text {disk }}=1.90 \mathrm{D}$ was obtained for hydrogen and methane jets, respectively. According to equations (2) and (5), the Mach disk height is related to the ratio of specific heats, hence, considering that hydrogen and nitrogen have very similar values of $\gamma$ (1.41 and 1.40, respectively), the predicted similarity of the Mach disk height for these two jets is noteworthy.

For under-expanded jets Ouellette and Hill [67] proposed a scaling relation for the jet tip penetration $Z_{\mathrm{t}}$ and the ratio of the upstream stagnation density to the ambient density $\rho_{0} / \rho_{\infty}$ as $Z_{t} /\left(\rho_{0} / \rho_{\infty}\right)^{1 / 4} \sim t^{1 / 2}$. Based on this, Vuorinen et al. [51] suggested a new scaling relation for the jet volume $V_{j e t}$ as $V_{j e t} /\left(\rho_{0} / \rho_{\infty}\right)^{3 / 4} \sim t^{3 / 2}$. Figures 5 and 6 show the tip penetration and volumetric growth for the different under-expanded jets of the current study based on those scaling parameters. Specifically, Figure 5 illustrates that using the scaling expression of Ouellette and Hill [67] collapsed the penetration lines onto almost a single line for hydrogen and methane with $\mathrm{NPR}=8.5$ and hydrogen with $\mathrm{NPR}=10$. The respective data of the hydrogen jets with $\mathrm{NPR}=30$ and 70 are also plotted in Figure 5 and will be discussed later in this paper. Figure 6 shows that the scaling expression of Vuorinen et al. [51] resulted in volumetric growth lines that have collapsed onto a 
single line for the hydrogen jets with $\mathrm{NPR}=8.5$ and 10 . However, the methane jet with $\mathrm{NPR}=8.5$ did not show a collapsed behaviour onto the same line to that of hydrogen. This can be a result of the much higher diffusivity of hydrogen in comparison to that of methane which can produce a considerably bulkier jet for hydrogen.

\subsection{Transient In-Nozzle Flow and Jet Development}

The current section investigates the transient formation of under-expanded jets in addition to the in-nozzle flow development within the early stages of injection. Initial transient stages of the near-nozzle shock expansion, Mach disk formation and jet development of the under-expanded hydrogen and methane jets are presented in Figure 7. Transient development of the in-nozzle (and within a short distance from the nozzle exit) axial Mach number for the hydrogen jet with NPR=10 is also shown in Figure 8 . The shock development and transient jet formation follow very similar trends for the hydrogen jets with NPR=8.5 and 10 in Figure 7. At $t \approx 13 t_{0}$ the Prandtl-Meyer expansion fans resulted in formation of a spherically propagating bow shock, followed by the growth of the first oblique shocks. According to Figure 8 , during $t \leq 11 t_{0}$ $\left(t \leq 6.8 \times 10^{-3} \mathrm{~ms}\right)$, the issuing jet was subsonic and then at $t \approx 13 t_{0}(t \approx 8.1 \mu \mathrm{s})$ the flow accelerated and reached $M a=1$ at the nozzle exit. Soon after that at $t \approx 21 t_{0}(t=13 \mu \mathrm{s})$, when the nozzle exit pressure $P_{1}$ reached the threshold of the under-expansion, i.e. $P_{1} / P_{\infty}>2$, a very small normal shock with narrowly spaced slip lines formed close to the nozzle exit (see Figure 7). This small normal shock can be assumed as the first appearance of the Mach disk. As it can be seen in Figure 8, during this time, the flow reached $M a=1$ upstream the nozzle exit (within the nozzle); the flow accelerated to $M a=1.02$ at the nozzle exit. At $t \approx 23 t_{0}$ $(t \approx 1.42 \mu \mathrm{s})$ a sudden rise occurred in the in-nozzle Mach number. Specifically, it reached $M a \approx 1.1$ and this was followed by a weak shock which caused the flow to decelerate and reach a value of $M a \approx 0.98$. The flow then accelerated again and reached a value of $M a=1.01$ at the nozzle exit. After this point, Figure 7 shows that as time passed, the distance between slip lines grew and the width of the Mach disk increased. Figure 8 shows that the position of $M a=1$ moved backwards upstream and was associated with an increase in the size of the Mach disk. As time passed, the position of $M a \approx 1$ moved further backwards; the Mach number inside the nozzle increased and the intensity of the inner nozzle shock was amplified (see Figure 8 ). When the Mach disk and shock structure close to the nozzle exit reached semi-steady conditions $\left(t \approx 80 t_{0}\right.$ or $\left.t \approx 49.6 \mu \mathrm{s}\right)$, $M a=1$ occurred about $0.5 D$ upstream the nozzle exit. A maximum Mach number of $M a \approx 1.3$ occurred at about $0.2 D$ upstream of the nozzle exit. From the time that the location of $M a=1$ started to occur inside the nozzle, it was noticed that the Mach number at the nozzle exit ranged from 1.01 at the beginning of the Mach disk formation to about 1.1 when the Mach disk dimensions had reached semi-steady conditions.

The observed development of the hydrogen jets with NPR=8.5 and 10 is in good agreement with the stages of shock development presented by Vuorinen et al. [51]. During the transient process it was noticed that the height and width of the Mach disk temporarily reached a higher value than their final steady state values. This can be seen for hydrogen jets in Figure 7 at $t \approx 32 t_{0}(t=20 \mu \mathrm{s})$ and at $t \approx 38 t_{0}(t=25 \mu \mathrm{s})$ with NPR of 10 and 8.5 , respectively. 
The transient development of the methane jet with $\mathrm{NPR}=8.5$ showed slightly different pattern to what was observed for hydrogen's jets with NPR=8.5 and 10. In particular, as shown in Figure 7, the methane jet contained strong expansion fans from the very beginning of its formation which resulted in the formation of a normal shock wider than the nozzle diameter very similar to a Mach disk. The distance of this normal shock from the nozzle exit increased quickly and at $t \approx 10 t_{0}(t=18 \mu \mathrm{s})$ the shock can be considered as a Mach disk which in conjunction with the intercepting shock form the first shock cell (barrel-shape shock). The dimensions of the barrel-shape shock were greater upon formation than the final steady values in the same way to what was observed earlier for the hydrogen jets. The existence of the wide Mach disk in the methane jet from the very beginning resulted in the development of widely-spaced slip lines, wider than those of the hydrogen jets where a slimmer Mach disk was formed initially.

Two test cases of hydrogen with NPR=30 and 70 were also studied. The transient formation of the hydrogen jet with NPR=30 is also presented in Figure 7. Due to the high NPR and strong compression fans the transient formation of the near-nozzle shock structure in this jet was very similar to what was described for the methane jet, specifically the formation of a wide Mach disk (normal shock) from very begging with widely-spaced slip lines. The hydrogen jet with $\mathrm{NPR}=70$ showed a similar transient behaviour to the that of $\mathrm{NPR}=30$. It is clear form Figure 7 that NPR had a considerable effect on the dimensions and shape of the Mach disk. It was observed that higher NPR produced more convex Mach disk. The propagation of a bow shock in front of the under-expanded jets can be seen in Figure 7 for all test cases.

The in-nozzle transient process described earlier for the hydrogen jet with NPR=10 (see Figure 8) was observed for all under-expanded methane and hydrogen jets of the current study. For a compressible methane flow in a macro-scale large-neck Laval nozzle of $2.4 \mathrm{~cm}$ throat diameter, Abdi et al. [68] studied the centreline Mach number and found that the choked condition of $M a=1$ occurred at the beginning of the constant area neck just after the converging area. They also noticed that the flow accelerated within the constant area throat and reached $M a \approx 1.35$; then it started oscillating around $M a \approx 1.2$ until it reached the exit plane of the constant area section (and beginning of the diffuser section). In contrast, the nozzle of the present study is categorized as a micro-nozzle and different flow behaviour is expected in comparison to larger scale counterparts [69-72]. For instance, in a micro-size convergent-divergent nozzle Hao et al. [72] noticed that, by scaling down the nozzle size, the Mach number at the throat and the nozzle exit decreased and the choked condition moved away from the throat towards the exit. The nozzle used in the current study had two sections, a converging part and constant area section with length of $0.6 D$ (Figure 2). As mentioned earlier, for all jets of the current at semi-steady conditions, $M a=1$ occurred at about $0.1 D$ downstream of the beginning of the constant area section. This can be explained by high compressibility effects [70] and high viscosity dissipation due to increased surface-to-volume ratio [72]. Just after the sonic line, expansion fans started forming and caused the flow to accelerate and reach a maximum Mach number of about 1.3 at about $0.2 D$ upstream of the nozzle exit where the reflected fans (from the nozzle wall) produced normal-shape shock which changed the flow condition to subsonic. After this point, the flow accelerated again through the re-reflected expansion fans and exited the nozzle with $M a \approx 1.1$. A Mach number higher that unity at the nozzle exit, $M a \approx 1.2$, was also observed in a study of Khaksarfard et al. [59] where hydrogen was injected 
with $P_{0}=34.5 \mathrm{MPa}$ into atmospheric ambient. However, in their work the presented injection duration was not long enough $(25 \mu \mathrm{s})$ to show the Mach number peak and the transient in-nozzle flow in the same way that was captured in the current study. In another study, where high pressure flow of nitrogen through an ejector device (vacuum jet) was investigated [73], the in-nozzle Mach number showed similar variations to those of the current study, as well as an exit Mach number higher than unity. Certainly further work is required in order to study in detail the behaviour of the in-nozzle transient compressible flow characteristics in tiny-sized nozzles. The effects of nozzle design and dimensions form a part of work in progress by the current authors and will be discussed in a future publication.

\subsection{Near-Nozzle Shock Structure}

Instantaneous snapshots of both methane and hydrogen jets with NPR=8.5 are shown in Figure 9. The greyscaling corresponds to density gradients as discussed earlier. Figure 9 also shows a close-up view of the near-nozzle shock structure of both jets at a semi-steady condition. The Prandtl-Meyer expansion fans, barrel-shape shock, Mach disk dimensions, as well as angle of reflected shock, triple points and slip lines, were all captured in very good agreement with the classic definition of an under-expanded jet [23-26] and also with computational results [49-51] and experimental visualisations [37] presented by other authors. Figure 9 also illustrates how the upper range of the legend in the grey-scaled images of $|\nabla \rho|$ can have significant effect on visualising details of the flow's characteristics. Specifically, decreasing the upper limit of the legend from $|\nabla \rho|=2,000$ to $|\nabla \rho|=500$ intensifies the clarity of the acoustic pressure waves emitted by the under-expanded jets. The pictures of Figure 9 are in great agreement with the LES visualisation of the under-expanded air jets of Dauptain et al. $[49,50]$. Table 3 presents quantitatively a comparison of the important near-field shock characteristics of the different under-expanded jets of the current study.

As mentioned earlier, the Mach disk height can be estimated using the empirical equations (1), (3), (5) and (7). For a specific substance these empirical relations can be adapted to:

$$
\frac{H_{\text {disk }}}{D}=C_{H} \times \sqrt{\frac{P_{0}}{P_{\infty}}}
$$

in which $C_{H}$ is an empirical constant that can be defined by the slope of the lines in Figure 10. Those lines are based on the results of the current study and on previously mentioned empirical relations. Figure 10 shows that the Mach disk height predicted by the current LES study is in agreement with the empirical relation of Ashkenaz and Sherman [29], i.e. equation (7), for $\left(P_{0} / P_{\infty}\right)^{0.5} \leq 5$. For higher values of $\left(P_{0} / P_{\infty}\right)^{0.5}$ though, the difference between the $H_{\text {disk }}$ of the current study and that of equation (7) increased and at $\left(P_{0} / P_{\infty}\right)^{0.5} \approx 8.4$ a difference of about $3.8 \%$ was quantified. The current study suggested a value of $C_{H}=0.71$ for the empirical constant of equation (22), particularly for under-expanded hydrogen jets. According to [59], $C_{H} \approx 0.67$ may not be accurate enough for injection pressures above $P_{0}=10 \mathrm{MPa}$. The current study suggests that in addition to the injection pressure, NPR is also important and for nozzle pressure ratios greater than about 70 the linear relation between $H_{\text {disk }} / D$ and $\left(P_{0} / P_{\infty}\right)^{0.5}$ may not be valid. 
As shown in Table 3, by increasing NPR from 8.5 to 10, the Mach disk height and width of the underexpanded hydrogen jet increased by $\sim 11 \%$ and $\sim 23 \%$, respectively. Then by increasing NPR from 10 to 30 an increase of $\sim 83 \%$ and $\sim 151 \%$ could be seen for the height and width of the Mach disk, respectively. This showed a considerably higher level of sensitivity of the width of the Mach disk to NPR in comparison to its height. The correlation suggested by Antsupov [27], i.e. equation (4), was also used to estimate the width of Mach disk and values of 1.065, 1.33, and 3.12 were obtained for NPR of 8.5, 10 and 30, respectively. According to Table 3, the current LES study predicted Mach disk width very close to equation (4) for $\mathrm{NPR}=8.5$ and 10 , whilst for NPR $=30$ a value higher by $\sim 8 \%$ was predicted by LES. Reordering equation (6) for the coefficient $\zeta$ and using values of Mach disk height and width obtained from the current LES work, $\zeta$ was estimated to be $\sim 0.72, \sim 0.80$ and $\sim 1.1$ for NPR of $8.5,10$, and 30 , respectively. Examining more nozzle pressure ratios could provide the opportunity to plot $\zeta$ versus NPR and consequently estimate the Mach disk width based on its height.

Direct comparison between the methane and hydrogen jets at NPR $=8.5$ (see Figure 9) reveals that the height of methane's Mach disk is $\sim 2.5 \%$ larger than that of hydrogen's. According to equations (2) and (5) the Mach disk height is weakly related to the ratio of specific heats. If the ratio of specific heats for hydrogen and methane is used to calculate the Mach disk height by equation (5) ( $\gamma \approx 1.41$ and 1.32, respectively), a difference of $2.1 \%$ is calculated between the two jets which is very close to the $2.5 \%$ predicted by LES. It was also found that the Mach disk width with $\mathrm{NPR}=8.5$ was $\sim 12 \%$ wider for methane than for hydrogen (see Table 3).

The angle of the reflected shock at the triple point was found to be $\beta=28.5^{\circ}$ for both methane and hydrogen jets with NPR=8.5, the same to that reported by Vuorinen et al. [51]. Increasing the NPR from 8.5 to 10 reduced the reflected shock angle slightly to $\beta=28^{\circ}$. It was noticed that further increase in NPR did not have any noticeable effect on the reflected shock angle and for $\mathrm{NPR}=30$ this was also $28^{\circ}$. For $\mathrm{NPR}=70$, the value of $\beta$ could not be measured with sufficient accuracy because the reflected shock was located outside of the refined area of the computational grid; however, based on observations of the present work and previous studies [51] it is believed that for NPR=70 the reflected shock angle would also be about $28^{\circ}$, i.e. beyond $\mathrm{NPR}=10$ the value of $\beta$ remains almost constant.

From Figure 9 it is evident that the shear layer thickness $\delta$ was wider for methane than for hydrogen. Specifically, for $\mathrm{NPR}=8.5$, the methane jet had $\delta \approx 0.47 D$ in comparison to $\delta \approx 0.22 D$ for hydrogen, i.e. the shear layer was wider by about $115 \%$ for methane. The value of $\delta$ for hydrogen is in satisfactory agreement with the value of $\delta \approx 0.25 D$ for the under-expanded nitrogen jet with NPR=8.5 of [51]. It was also noticed that by increasing the NPR from 8.5 to 10 and then to 30 the shear layer thickness reduced by about $3 \%$ and $19 \%$, respectively (see Table 3 ).

\subsection{Flow Characteristics of Under-Expanded Jets}

Instantaneous snapshots of fuel mole fraction $\left(\mathrm{H}_{2}\right.$ or $\left.\mathrm{CH}_{4}\right)$, temperature, velocity and Mach number are presented at $t=0.2 \mathrm{~ms}$ after the start of injection in Figure 11 for various values of NPR. A semi opaque mask has been applied on these snapshots to highlight the main region of interest in the core of the jets. Hydrogenair mixing prior to the location of the Mach disk is evident. It is also clear that for the same NPR of 8.5 , the 
hydrogen jet was more voluminous than the methane jet. This can be explained by the lower density and higher diffusivity of hydrogen which speed up the mixing process and increase the radial penetration rate of hydrogen in comparison to methane. Furthermore, it is also clear that the fuel core with $X \approx 1$ penetrated further in the axial direction with hydrogen than with methane. Very similar spatial variation of mole fraction was noticed between hydrogen jets with $\mathrm{NPR}=8.5$ and $\mathrm{NPR}=10$. For $\mathrm{NPR}=30$ the hydrogen mole fraction snapshot of Figure 11 displays clearly a wider jet in which the majority of the highlighted area had $X \geq 0.7$ and the core with $X \approx 1$ penetrated beyond the area shown in the snapshots.

The temperature snapshot in Figure 11 shows that the temperature of the methane jet with NPR=8.5 dropped to $T \approx 103 \mathrm{~K}$ just upstream of the Mach disk, whereas it dropped to $T \approx 77 \mathrm{~K}$ for hydrogen at the same NPR. It was also found that for hydrogen with NPR of 10 and 30 the temperature at the vicinity of the Mach disk dropped to $T \approx 71 \mathrm{~K}$ and $T \approx 41 \mathrm{~K}$, respectively. It worth noting here that for the simulated hydrogen jets, the near-nozzle temperature distribution may not be accurate due to the negative Joule-Thomson coefficient of hydrogen which cannot be captured by employing ideal gas assumptions. However, according to [59, 60], even use of a real gas EoS, temperatures near to cryogenic conditions (similar to those of the present work) would be measured upstream of the Mach disk for under-expanded hydrogen jets. Figure 12 presents the axial temperature (i.e. on the centre-line of the chamber) normalized by the nozzle exit temperature calculated by LES ( $T_{1} \approx 248 \mathrm{~K}$ and $T_{1} \approx 235 \mathrm{~K}$ for methane and hydrogen, respectively) is presented. It is noted that the axial temperature did not exceed the ambient temperature for both methane and hydrogen fuels, whilst [60] has shown that a real gas EoS would predict a higher temperature than the ambient temperature just after the Mach disk by $\sim 15 \%$.

The corresponding instantaneous snapshot of the spatial distribution of the velocity magnitude is also shown in Figure 11. It was found that the velocity in the methane jet with NPR=8.5 reached a maximum value of $U=927 \mathrm{~m} / \mathrm{s}$ at the vicinity of the Mach disk, whereas for the same NPR the hydrogen jet reached a maximum velocity of $U=2,493 \mathrm{~m} / \mathrm{s}$. For under-expanded hydrogen jets with $\mathrm{NPR}=10$ and NPR=30 a maximum velocity of $U=2 \mathrm{~m} 531 \mathrm{~m} / \mathrm{s}$ and $U=2,695 \mathrm{~m} / \mathrm{s}$ was observed, respectively. The nozzle exit velocity $\left(U_{1}\right)$ was calculated by LES to be $U_{1}=458 \mathrm{~m} / \mathrm{s}$ for methane, $U_{1} \approx 1,305$ for hydrogen with $\mathrm{NPR}=8.5,10$ and 30 and $U_{1}=1,311$ for hydrogen with NPR=70. It was noted that the maximum value of normalized axial velocity $\left(U / U_{1}\right)$ for the methane jet was 2.02 and for the hydrogen jets with $\mathrm{NPR}=8.5,10,30$, and 70 this was 1.90, 1.93, 2.06 and 2.11 , respectively. This is in satisfactory agreement with the $U / U_{1}$ graph presented in [28] for an underexpanded air jet with $\mathrm{NPR}=30$.

Instantaneous snapshots of $M a$ are also included in Figure 11. Several shock cells and high velocity $(M a>1)$ slip regions after the Mach disk can be seen clearly. Figure 13 shows the variation of the axial Mach number on the centre-line. Cross-analysis of Figure 11 with Figure 13 revealed that the maximum centre-line $M a$ was not necessary the maximum Mach number within the under-expanded jet. As shown in Figure 11, the maximum Mach number in the vicinity of the Mach disk for methane with NPR=8.5 was $M a=3.51$, whilst for hydrogen with $\mathrm{NPR}=8.5,10$, and 30 this was $M a=3.72,3.96$, and 5.53, respectively. Figure 13 shows slightly lower values for the axial Mach number specifically $M a=3.48$ for methane and $M a=3.68,3.89$, and 
5.44 for hydrogen with NPR=8.5, 10 and 30, respectively. The maximum axial Mach number for the underexpanded hydrogen jet with NPR=70 was $M a=6.73$.

As explained earlier in the current work (and also described in detail in reference [25]), after the Mach disk and depending on the level of NPR, the flow can accelerate and reach $M a \approx 1$ several times. In the present work for methane at NPR=8.5 and hydrogen at NPR=8.5 and 10 it was noticed that just after the Mach disk the subsonic flow started accelerating and after a specific distance $(\mathrm{z} / D=3.016,3.205$ and 3.306, respectively) it started slowing down. For the hydrogen jet with NPR $=8.5$ the acceleration process caused the jet to reach $\mathrm{Ma} \approx 1.01$ therefore the acceleration length and the length of the subsonic core just after the Mach disk were the same and equal to $l_{\text {sub }} \approx 1.35 D$. The Mach number in the methane jet of NPR=8.5 and the hydrogen jet of $\mathrm{NPR}=10$ reached the maximum values of $M a \approx 0.74$ and $M a \approx 0.82$, respectively. Then, further downstream, a second acceleration process led to $M a>0.9$, i.e. to the sonic threshold. For the hydrogen jet with NPR $=30$, past the Mach disk, the jet started fluctuating in the range of $M a=0.6-0.7$. At $\mathrm{z} / D \approx 5.1$ the jest reached $M a=0.91$ which created a subsonic length of $l_{\text {sub }} \approx 3.8 D$. For the hydrogen jet with NPR=70 no major flow acceleration was noticed past the Mach disk and the jet continued decaying in a subsonic manner, similarly to what has been described in [25].

Figures 14 and 15 illustrate the axial pressure $(P)$ and normalized axial density $\left(\rho / \rho_{1}\right)$ (i.e. on the centre-line of the chamber) for the methane and hydrogen jets. A higher transient fluctuation of both axial pressure and normalized axial density was seen for hydrogen with $\mathrm{NPR}=8.5$ in comparison to the methane jet at the same NPR; this indicated higher compressibility effects for the hydrogen jet. In the vicinity of the Mach disk for the methane jet and hydrogen jets with $\mathrm{NPR}=8.5,10$ and 30, the pressure reached a value higher than the ambient pressure and then started fluctuating around the ambient value. For hydrogen with NPR=70, the pressure jumped to a value lower than the ambient just after the Mach disk and then increased, but with a lower level of fluctuation in comparison to the other test cases. Hydrogen's density dropped to values as low as $\sim 0.02 \mathrm{~kg} / \mathrm{m}^{3}$ and then increased almost instantly past the Mach disk due to the normal shock recompression. After the Mach disk location, density increased towards the ambient value via a fluctuating pattern. It was noticed that a lower NPR would result in higher density fluctuations and, consequently, a faster growth rate of the jet's axial density. The nozzle exit density $\left(\rho_{1}\right)$ for the methane jet with NPR=8.5 and for the hydrogen jets with $\mathrm{NPR}=8.5,10,30$ and 70 was $3.04,0.39,0.46,1.37$ and $3.23 \mathrm{~kg} / \mathrm{m}^{3}$, respectively. These values resulted in respective mass flow rates of $2.46,0.90,1.06,3.16$ and $7.49 \mathrm{~g} / \mathrm{s}$.

As seen in Figure 16, the nozzle exit pressure and mass flow rate of the under-expanded hydrogen jets were linearly related to the NPR; a similar linear relationship has been reported by Vuorinen et al. [51]. In comparison to the LES studies of nitrogen jets of [51], the current LES work of under-expanded hydrogen jets predicted lower variation rates for the nozzle exit pressure and nozzle exit mass flow rate versus NPR. This is believed to be due to differences in nozzle design and also different compressibility effects of the two different working gases. It is also worth mentioning that both the current study and the work presented in [51] confirmed that in high-pressure gaseous injectors the actual nozzle exit conditions, such as exit pressure, may not follow isotropic relations [53] such as $P_{1}=0.528 P_{0}$. Therefore, simulating the in-nozzle flow of under-expanded jets is necessary to obtain accurate conditions at the nozzle exit. 


\subsection{Mixing Characteristics}

As seen in Figures 4 and 9, methane-air mixing did not occur before the Mach disk. In contrast, the strong fluctuations at the jet boundary before the Mach disk of the hydrogen jet represented considerable level of momentum exchange and mixing just by the border of the barrel-shape shock. This mixing is associated with Gortler vortices that are characterized by the Gortler number defined as $[51,74,75]$ :

$$
G=\frac{U_{s} \theta}{v}\left(\frac{\theta}{r}\right)^{1 / 2}
$$

where $U_{s}$ is a velocity scale, $\theta$ is the momentum thickness of incoming boundary layer, $r$ is the radius of the shock cell curvature and $v$ is the kinematic viscosity. According to [51], if $G$ exceeds $\sim 0.3$ in under-expanded jets, Gortler vortices (i.e. mixing) may occur outside the barrel-shape shock before the Mach disk location. $U_{s}$ is considerably greater for hydrogen than for methane (by about 3 times) due to the faster rate of acoustic waves propagation in hydrogen; see equation (20). Figure 9 also illustrates that for hydrogen jetting, $\theta$ is considerably larger than for methane. The radius of the barrel-shape shock curvature was almost similar for both jets. Therefore, the high kinematic viscosity of hydrogen, $v_{\mathrm{H} 2}=110 \times 10^{-6} \mathrm{~m}^{2} / \mathrm{s} v s . v_{\mathrm{CH} 4}=17.2 \times 10^{-6} \mathrm{~m}^{2} / \mathrm{s}$ [15] at atmospheric conditions, cannot overcome the effect of $U_{s}$ and $\theta$, thus a noticeable higher Gorlter number is expected for hydrogen jet than for methane.

The jet tip penetration for the methane and hydrogen jets with various nozzle pressure ratios is plotted in Figure 17. For NPR $=8.5$, after the initial transient process $(t \approx 0.075 \mathrm{~ms})$, the hydrogen jet penetrated $\sim 40 \%$ more than the methane jet, thus faster mixing is expected in an engine with hydrogen fuelling. As shown earlier in the mole fraction snapshot of Figure 11, hydrogen produced a wider jet that methane did. Therefore, a higher value of NPR is required for methane injection in order to deliver comparable mixing characteristics to hydrogen with $\mathrm{NPR}=8.5$. For both methane and hydrogen, the primary mixing started after the Mach disk location, particularly closer to the jet boundaries where intense turbulence seemed to play a dominant role in the mixing process.

It was also observed that the hydrogen jet with $\mathrm{NPR}=10$ had longer penetration by $\sim 5 \%$ in comparison to the hydrogen jet with $\mathrm{NPR}=8.5$. On the other hand, within the initial injection duration (typically up to $t \approx 0.065$ $\mathrm{ms}$ ), the hydrogen jets with $\mathrm{NPR}=30$ and 70 penetrated more than the hydrogen jet with $\mathrm{NPR}=10$ (longer penetration observed for $\mathrm{NPR}=70$ ). After the initial transient period, the jet with $\mathrm{NPR}=70$ continued to penetrate with a rate similar to the hydrogen jet with $\mathrm{NPR}=8.5$, whereas the hydrogen jet with $\mathrm{NPR}=30$ continued to penetrate with even lower rate ( $\sim 8 \%$ less). This behaviour of the hydrogen jets with NPR $=30$ and 70 can be regarded as the result of the noticeably wider jet in comparison to NPR=8.5 and 10 . A similar trend was noticed by Owston et al. [76] where for hydrogen jets with similar mass flow rates, NPR $\approx 20$ produced lower penetration than $\mathrm{NPR} \approx 10$. They concluded that inadequate grid resolution caused this to occur [76]. However, in the current study where according to the literature [49-51] the grid resolution has been fine enough to capture details of under-expanded jets, a similar trend was observed, even for jets with different mass flow rates. Therefore, it can be assumed that there could be a trade-off between the width and penetration of hydrogen and that there should be an optimum NPR that can provide desirable penetration (which can enhance mixing), whilst also delivering enough fuel within an appropriate injection duration. 
As discussed earlier in the validation section, Vuorinen et al. [51] reported that NPR is proportional to the jet volume with an exponent of $3 / 4$; consequently, they concluded that NPR had little effect on the mixture richness. This may be valid for less diffusive jets and for low level of nozzle pressure ratios $($ e.g. NPR $<10)$, as well as when comparing jets with NPR varied over a narrow range (e.g. NPR=4-9 examined by the latter authors). The current study suggests that for under-expanded hydrogen jets, considerably richer mixture could be produced if high NPR values, like 30 and 70 , were applied instead of NPR $\leq 10$. This can be observed in the mole fraction contours of Figure 11 where for hydrogen with NPR $=30$ the refined area had almost $X>0.75$, whereas the hydrogen jets with NPR $=8.5$ and 10 demonstrated considerably leaner mixtures within the refined area and a similar spatial variation of mole fraction to each other.

Higher NPR leads to more enhanced mixing and entrainment [51] and according to the present study it can also supply richer mixture in less time. Hence, based on the mole fraction contours of Figure 11 and the penetration lengths of Figure 17, a value of NPR in the region of 100 could be an optimum strategy for hydrogen DI since it would produce a richer jet with higher penetration compared to NPR=10 and deliver more fuel in less time. Certainly further investigation is necessary in order to make a solid conclusion, especially for hydrogen jets with NPR $>70$ and in smaller scale nozzles. It worth mentioning here that in DI hydrogen-fuelled IC engines, the main air-fuel mixing occurs after the hydrogen jet's wall impingement, e.g. see $[18,22]$. In the present work a penetration length of $\sim 3.5 \mathrm{~cm}$ (the length of the refined area) was studied; this falls within the range of $2-5 \mathrm{~cm}$ that a hydrogen jet needs to penetrate in a typical IC engine geometry before impinging onto a surface of the cylinder liner or piston crown (depending on injection strategy and injector position). Further study is needed to investigate the characteristics of hydrogen penetration with longer injection durations (thus over longer distances), e.g. for hydrogen safety considerations.

\section{SUMMARY AND CONCLUSIONS}

The current computational study used LES to investigate the near-nozzle shock structure and mixing characteristics of under-expanded hydrogen jets. Direct comparison was conducted between hydrogen and methane jets with NPR $=8.5$. The effects of increasing NPR on under-expanded hydrogen jets were further examined by enabling use of various values of NPR, namely 8.5, 10, 30 and 70. The computational framework was initially validated against experimental and computational test cases available in the literature. Reference parameters of the near-field shock structure, i.e. Mach disk height and width, reflected shock angle, length of subsonic core after the Mach disk and shear layer thickness were quantified. The development of the transient under-expanded jets, in addition to the transient behaviour of in-nozzle compressible flow, was investigated. Important mixing characteristics of under-expanded jets with respect to IC engine applications, e.g. jet tip penetration and volumetric growth, were examined for both hydrogen and methane jets. The main conclusions of this work can be summarised as follows:

- The near-field shock structure, i.e. Prandtl-Meyer expansion fans, barrel-shape shock, Mach disk dimensions, reflected shock at the triple point and slip line were all predicted in very good agreement with the classic definition of under-expanded jets and with data available in the literature. 
- During the initial transient process the height and width of the Mach disk of both methane and hydrogen jets temporarily reached higher values than those observed at steady state.

- The near-nozzle shock structure of the methane jet with NPR=8.5 showed slightly different pattern to the hydrogen jets of $\mathrm{NPR}=8.5$ and 10 . The methane jet contained strong expansion fans from the very beginning of its formation and resulted in a normal shock wider than the nozzle diameter that was very similar to a Mach disk. In turn, this led to widely-spaced slip lines in comparison to those of the hydrogen jets which were associated with a slim Mach disk.

- For hydrogen with NPR=30, the transient formation of the near-nozzle shock structure was comparable to that of the methane jet with NPR=8.5, i.e. with presence of a wide Mach disk (normal shock) from the very beginning and widely-spaced slip lines.

- The height and width of the Mach disk were very sensitive to NPR. A higher degree of sensitivity was noticed for the width of the disk than for its height. Increasing NPR from 10 to 30 for hydrogen resulted in an increase of $83 \%$ and $150 \%$ in the height and width of the Mach disk, respectively.

- The methane jet with NPR=8.5 had larger height and width by $2.5 \%$ and $12 \%$, respectively, than the corresponding hydrogen jet, potentially due to the lower ratio of specific heats $(\gamma)$ of methane.

- For methane, mixing did not occur before the Mach disk, whereas for hydrogen high level of momentum exchange and mixing was observed at the boundaries of the jet. This is believed to be related to the effect of higher turbulent fluctuations at the nozzle exit and the larger Gortler number for hydrogen which triggered the presence of Gortler vortices and initiated the mixing process.

- For all under-expanded jets at semi-steady conditions, chocked flow of $M a \approx 1$ occurred inside the nozzle volume at about $0.5 \mathrm{D}$ upstream of the nozzle exit. A maximum $M a$ of about 1.3 was calculated about $0.2 D$ upstream of the nozzle exit whilst the nozzle exit $M a$ was about 1.1. Considering the small scale of the nozzle, high viscosity dissipation due to large surface-to-volume ratio and also exceptional compressible effects are potential reasons for this behaviour. However, more work is required in order to clarify the in-nozzle transient hydrogen flow behaviour of small-size nozzles.

- The angle of the reflected shock at the triple point was $28.5^{\circ}$ for both methane and hydrogen fuelling with NPR=8.5. Increasing NPR from 8.5 to 10 reduced slightly the reflected shock angle to $28^{\circ}$, whilst further increase in NPR did not have any noticeable effect on this angle.

- For NPR $=8.5$ the shear layer thickness was wider for methane than for hydrogen by $114 \%$. Increasing NPR for hydrogen from 8.5 to 10 and then 30 led to a narrower shear layer by $3 \%$ and $19 \%$, respectively.

- The difference between methane and hydrogen jets in terms of the penetration length and volumetric growth was found to come from differences in both sonic characteristics and diffusivity. The sonic characteristics of the two jets were different due to differences in the ratio of specific heats and density. This resulted in hydrogen reaching higher supersonic velocities than methane and considerably higher penetration. Additionally, the higher diffusivity of hydrogen resulted in the formation of a bulkier jet (due to accelerated radial mixing) compared to methane fuelling. 
- It was confirmed that both the nozzle exit pressure and nozzle mass flow rate of under-expanded hydrogen jets were linearly related to NPR. For NPR $=8.5$ the hydrogen jet penetrated about $40 \%$ more than the methane jet, thus faster in-cylinder mixing is expected for hydrogen. Higher NPR was required for methane in order to deliver comparable mixing characteristics to those of a hydrogen jet.

- Higher NPR did not necessarily increase the hydrogen jet's penetration. After the initial transient process of $\sim 0.1 \mathrm{~ms}$, the jet with $\mathrm{NPR}=70$ showed a penetration length comparable to that with $\mathrm{NPR}=8.5$. $\mathrm{NPR}=30$ produced even lower penetration by about $8 \%$. NPR $=100$ could be the optimum for hydrogen injection with the current geometry but further study is needed for a widely applicable conclusion.

- Values of NPR in excess of 30 can have significant effect on the mixture richness within under-expanded hydrogen jets and can provide richer mixture in less time.

- For all methane and hydrogen jets studied in the current work, the main mixing was observed to start after the Mach disk location and particularly close to the jet boundaries where intense turbulence was noticed to play a dominant role in the mixing process.

Finally it should be noted that the in-cylinder operating conditions of hydrogen-fuelled engines can be significantly different from the ambient conditions used within the objectives of the current study, i.e. elevated pressures and temperatures, depending on injection timing. However, although the conditions used here are representative primarily of processes with early injection strategies (i.e. intake stoke and early compression stroke injection timings), the different NPR values used in the current study provided significant information regarding characteristics of under-expanded transient jets and in-nozzle gaseous flow behaviour which can be used to design advanced high pressure gaseous injection systems including highpressure hydrogen injectors. Additionally, it is noted that for under-expanded jets the sonic characteristics do not depend on the downstream condition (in-cylinder) and are primarily affected by the level of NPR. For instance let's consider two jets with NPR=10 which the first one is injected with 10 bar into 1 bar ambient and the other one is injected into a 10 bar ambient with 100 bar injection pressure. The near-nozzle shock structure for both jets would be expected to be quite similar. However, mixing characteristics particularly downstream of the Mach disk would be different. The characteristics of under-expanded hydrogen and methane jets under elevated conditions of ambient pressure and temperature are also being investigated by the current authors and will be discussed in a future publication.

\section{ACKNOWLEDGEMENTS}

The authors acknowledge the use of University College London's Legion High Performance Computing Facility (Legion@UCL) and associated support services in the completion of this work. The authors would also like to thank all members of the UCL Internal Combustion Engines Group for their assistance and many valuable discussions. 


\section{REFERENCES}

[1] Bokris J. O'M., The Origin of Ideas on a Hydrogen Economy and its Solution to the Decay of the Environment, International Journal of Hydrogen Energy, Vol. 27, 2002, pp. 731-740.

[2] Lattin W.C., and Utgikar V.P., Transition to hydrogen economy in the United States: A 2006 status report, International Journal of Hydrogen Energy, Vol. 32, 2007, pp. 3230-3237.

[3] White C.M., Steeper R.R., and Lutz A.E., The hydrogen-fueled internal combustion engine: A technical review, International Journal of Hydrogen Energy, Vol. 31, 2006, pp. 1292-1305.

[4] Verhelst S., and Wallner T., Hydrogen-fueled internal combustion engines, Progress in Energy and Combustion Science, Vol. 35, 2009, pp. 490-527.

[5] Al-Baghdadi M., and Al-Janabi H.A., A prediction study of a spark ignition supercharged hydrogen engine, Energy Conversion and Management, Vol. 44, 2003, pp. 3143-3150.

[6] Berckmüller M., Rottengruber H., Eder A., Brehm N. et al., Potentials of a Charged SI-Hydrogen Engine, SAE Technical Paper 2003-01-3210, 2003.

[7] Verhelst S., and Sierens R., Combustion Studies for PFI Hydrogen IC Engines, SAE Technical Paper 2007-01-3610, 2007.

[8] Verhelst S., Maesschalck P., Rombaut N., and Sierens R., Increasing the power output of hydrogen internal combustion engines by means of supercharging and exhaust gas recirculation, International Journal of Hydrogen Energy, Vol. 34, 2009, pp. 4406-4412.

[9] Kawahara N., and Tomita E., Visualization of auto-ignition and pressure wave during knocking in a hydrogen spark-ignition engine, International Journal of Hydrogen Energy, Vol. 34, 2009, pp. 3156-3163.

[10] Rakopoulos C.D., Kosmadakis G.M., and Pariotis E.G., Evaluation of a combustion model for the simulation of hydrogen spark-ignition engines using a CFD code, International Journal of Hydrogen Energy, Vol. 35, 2010, pp. 12545-12560.

[11] Rakopoulos C.D., Kosmadakis G.M., Demuynck J., De Paepe M., and Verhelst S., A combined experimental and numerical study of thermal processes, performance and nitric oxide emissions in a hydrogen-fueled spark-ignition engine, International Journal of Hydrogen Energy, Vol. 36, 2011, pp. 51635180.

[12] Aleiferis P.G., and Rosati M.F., Flame chemiluminescence and OH LIF imaging in a hydrogen-fuelled spark-ignition engine, International Journal of Hydrogen Energy, Vol. 37, 2012, pp. 1797-1812.

[13] Kaiser S. and White C., PIV and PLIF to Evaluate Mixture Formation in a Direct-Injection HydrogenFuelled Engine, SAE Int. J. Engine, 2009, pp. 657-668.

[14] Wallner T., Nande A., and Naber J., Evaluation of Injector Location and Nozzle Design in a DirectInjection Hydrogen Research Engine, SAE Technical Paper 2008-01-1785, 2008.

[15] Rosati M., and Aleiferis, P.G., Hydrogen SI and HCCI Combustion in a Direct-Injection Optical Engine, SAE Int. J. Engines, 2009, pp. 1710-1736.

[16] Scarcelli R., Wallner T. Salazar V., and Kaiser S., Modeling and Experiments on Mixture Formation in a Hydrogen Direct-Injection Research Engine, SAE Int. J. Engines, 2010, pp. 530-541. 
[17] Salazar V. and Kaiser S., An Optical Study of Mixture Preparation in a Hydrogen-fueled Engine with Direct Injection Using Different Nozzle Designs, SAE Int. J. Engines 2010, 119-131.

[18] Scarcelli R., Wallner T., Matthias N., Salazar V. et al., Mixture Formation in Direct Injection Hydrogen Engines: CFD and Optical Analysis of Single- and Multi-Hole Nozzles, SAE Int. J. Engines, 2011, pp. 2361-2375.

[19] Roy M., Kawahara N., Tomita E., and Fujitani T., High-Pressure Hydrogen Jet and Combustion Characteristics in a Direct-Injection Hydrogen Engine, SAE Int. J. Fuels Lubr., 2012, pp. 1414-1425.

[20] Nakagawa K., Yamane K., and Ohira T., Potential of Large Output Power, High Thermal Efficiency, Near-zero NOx Emission, Supercharged, Lean-burn, Hydrogen-fuelled, Direct Injection Engines, Energy Procedia, Vol. 29, 2012, pp. 455-462.

[21] Aleiferis P.G., and Rosati M.F., Controlled autoignition of hydrogen in a direct-injection optical engine, Combustion and Flame, Vol. 159, 2012, pp. 2500-2515.

[22] Hamzehloo A., and Aleiferis, P.G, Computational Study of Hydrogen Direct Injection for Internal Combustion Engines, SAE Technical Paper 2013-01-2524, 2013.

[23] Crist S., Sherman P. M., and Glass D. R., Study of the highly underexpanded sonic jet, AIAA J. Vol. 4, 1966, pp. 68-71.

[24] Abbett M., The Mach Disk in Underexpanded Exhaust Plumes, AIAA Journal, Vol. 9, 1971, pp. 512514.

[25] Donaldson C. DuP., and Snedeker R. S. 1971 A study of free jet impingement. Part 1. Mean properties of free and impinging jets. J. Fluid Mech. 1971, Vol. 45, pp. 281-319.

[26] Ewan BCR, Moodie K, Structure and velocity measurements in underexpanded jets, Combustion Science and Technology 1986; Vol. 45, pp. 275-288.

[27] Antsupov A.V., Properties of underexpanded and overexpanded supersonic gas jets. Soviet Physics and Technical Physics, 1974, Vol. 19, pp. 234-238.

[28] Velikorodny A., and Kudriakov S., Numerical study of the near-field of highly underexpanded turbulent gas jets, International Journal of Hydrogen Energy, Vol. 37, 2012, pp. 17390-17399.

[29] Ashkenas H., and Sherman F.S., The structure and utilization of supersonic free jets in low density wind tunnel. In Advances in Applied Mechanics_-Rarefied Gas Dynamics. Academic Press: New York, 1965, pp. 84-105.

[30] Turner J.S., The starting plume in neutral surroundings, J. Fluid Mech, Vol.13, 1962, pp. 356-368.

[31] Hill P.G., and Ouellette P., Transient turbulent gaseous fuel jets for diesel engines, Journal of Fluids Engineering, Vol.121, 1999, pp. 93-101.

[32] Abraham J., Entrainment characteristics of transient gas jets, Numerical Heat Transfer, Vol.30, 1996, pp. 3478-364.

[33] Petersen B., and Ghandhi J., Transient High-Pressure Hydrogen Jet Measurements, SAE Technical Paper 2006-04-03, 2006.

[34] Chuech S.G., Lai M.C., and Faeth G.M., Structure of turbulent sonic underexpanded free jets, AIAA Journal, Vol. 27, 1989, pp. 549-556. 
[35] Panda J., and Seasholtz R. G., Measurement of shock structure and shock-vortex interaction in underexpanded jets using Rayleigh scattering, Phys. Fluids, Vol. 11, 1999.

[36] Yuceil K.B., and Otugen M.V., Scaling parameters for underexpanded supersonic jets, Physics of Fluids, Vol. 14, 2002.

[37] Yu J., Vuorinen V., Hillamo H., Sarjovaara T. et al., An Experimental Study on High Pressure Pulsed Jets for DI Gas Engine Using Planar Laser-Induced Fluorescence, SAE Technical Paper 2012-01-1655, 2012.

[38] Prudhomme S. M., Haj-Hariri H, Investigation of supersonic underexpanded jets using adaptive unstructured finite elements, Finite Elements in Analysis and Design, Vol. 17, 1994, pp. 21-40,

[39] Irie T., Yasunobu T., Kashimura H., and Setoguchi T., Characteristics of the Mack Disk in the underexpanded jet in which the back pressure continuously changes with time, Journal of Thermal Science, Vol. 12, 2003, pp. 132-137.

[40] Cheng T. S. and Lee K. S., Numerical simulations of underexpanded supersonic jet and free shear layer using WENO schemes, International Journal of Heat and Fluid Flow, Vol. 26, 2005, pp. 755-770.

[41] Suzuki H., Endo M., and Sakakibara Y., Structure and Oscillation of Underexpanded Jet, Open Journal of Fluid Dynamics, Vol. 3, 2013, pp. 85-91.

[42] Dubs P., Khalij M., Benelmir R., and Tazibt A., Study on the dynamical characteristics of a supersonic high pressure ratio underexpanded impinging ideal gas jet through numerical simulations, Mechanics Research Communications, Vol. 38, 2011, pp. 267-273.

[43] Chauvet N., Deck S., and Jacquin L., Numerical Study of Mixing Enhancement in a Supersonic Round Jet, AIAA Journal, Vol. 45, 2007, pp. 1675-1687.

[44] Lehnasch G., and Bruel P., A robust methodology for RANS simulations of highly underexpanded jets, International Journal for Numerical Methods in Fluids, Vol. 56, 2008, pp. 2179-2205.

[45] White T., Milton B., 2008. Shock wave calibration of under expanded natural gas fuel jets. Shock Waves, Vol. 18, 2008, pp. 353-364.

[46] Chin C., Li M., Harkin C., Rochwerger T., Chan L., and Ooi A., Investigation of the Flow Structures in Supersonic Free and Impinging Jet Flows, Journal of Fluids Engineering, Vol. 135, 2013.

[47] Chauvet N., Deck S., and Jacquin L., Zonal Detached Eddy Simulation of a Controlled Propulsive Jet, AIAA Journal, Vol. 45, 2007, pp. 2458-2473.

[48] Deck S., Delayed detached eddy simulation of the end-effect regime and side-loads in an overexpanded nozzle flow, Shock Waves, 2009, Vol. 19, pp. 239-249.

[49] Dauptain A., Cuenot B., and Gicquel Y.M., Large-eddy simulation of a stable supersonic jet impinging on flat plate, AIAA J. Vol. 48, 2010, pp. 2325-2337.

[50] Dauptain A., and Gicquel Y.M., Large Eddy Simulation of Supersonic Impinging Jets, AIAA J. Vol. 50, 2012, pp. 1560-1574.

[51] Vuorinen V., Yu J., Tirunagari S., Kaario O., Larmi M., et al, Large-eddy simulation of highly underexpanded transient gas jets, Phys. Fluids, Vol. 23, 2011. 
[52] Yu J., Vuorinen V., Kaario O., Sarjovaara T., and Larmi M., Visualization and analysis of the characteristics of transitional underexpanded jets, International Journal of Heat and Fluid Flow, Vol. 44, 2013, pp. 140-154.

[53] Anderson J. D., Modern compressible flow: with historical prespective, $3^{\text {rd }}$ Edition, McGraw-Hill, 2003.

[54] Roe P.L., Approximate Riemann solvers, parameter vectors, and difference schemes, Journal of Computational Physics, Vol. 43, 1981, pp. 357-372

[55] Liou M. S., and Steffen C. J., A New Flux Splitting Scheme, Journal of Computational Physics, Vol. 107, pp. 23-39, 1993.

[56] Ruggles A.J., and Ekoto I.W., Ignitability and mixing of underexpanded hydrogen jets, International Journal of Hydrogen Energy, Vol. 37, 2012, pp. 17549-17560.

[57] Gorlé C., and Gamba M., Ham F., Investigation of an underexpanded hydrogen jet in quiescent air using numerical simulations and experiments, Annual Research Briefs 2010, Center for Turbulence Research, Stanford University.

[58] Gorlé C., and Iaccarino G., Large eddy and Reynolds-Averaged Navier-Stokes simulations of an underexpanded sonic jet, 7th European Symposium on Aerothermodynamics, European Space Agency, Netherlands, 2011.

[59] Khaksarfard R., Kameshki M. R., and Paraschivoiu M., Numerical simulation of high pressure release and dispersion of hydrogen into air with real gas model, Shock Waves, Vol. 20, 2010, pp. 205-216.

[60] Bonelli F., Viggiano A., and Magi V., A Numerical Analysis of Hydrogen Underexpanded Jets Under Real Gas Assumption, Journal of Fluids Engineering, Vol. 135, 2013.

[61] Weiss J. M., and Smith W. A., Preconditioning Applied to Variable and Constant Density Flows, AIAA J., Vol. 33, 1995, pp. 2050-2057.

[62] Weiss J. M., Maruszewski J. P., and Smith W. A., Implicit Solution of Preconditioned Navier-Stokes Equations Using Algebraic Multigrid, AIAA J., Vol. 37, 1999, pp. 29-36.

[63] Nicoud F., and Ducros F., Subgrid-Scale Stress Modelling Based on the Square of the Velocity Gradient Tensor, Flow, Turbulence and Combustion, Vol. 62, 1999, pp. 183-200.

[64] Cussler E.L., Diffusion: mass transfer in fluid systems, Third edition, Cambridge University Press, 2009.

[65] Hirschfelder J.O., Curtiss C.F., and Bird R.B., Molecular Theory of Gases and Liquids, John Wiley \& Sons, Second Edition, 1964.

[66] Gad-el-Hak M., The Fluid Mechanics of Microdevices - The freeman Scholar Lecture, 1999, Journal of Fluid Engineering, pp. 5-33.

[67] Ouellette P., Hill P.G., Turbulent Transient Gas Injections, Journal of Fluid Engineering, 2000, pp. 743753.

[68] Abdi M.A., Jassim E., Haghighi M., and Muzychka Y., Applications of CFD in Natural Gas Processing and Transportation, Computational Fluid Dynamics, 2010, Hyoung Woo Oh (Ed.).

[69] Ho C., and Tai Y., Micro-Electro-Mechanical-Systems (MEMS) and Fluid Flows, Annual Reviews Fluid Mechanics, Vol. 30, 1998, pp. 579-612. 
[70] Jie D., Diao X., Cheong K.B., and Yong L.K., Navier-Stokes simulations of gas flow in micro devices, Journal of Micromechanics and Microengineering, Vol. 10, 2000, pp. 372-379.

[71] Rostami A.A., Mujumdar A.S., and Saniei N., Flow and heat transfer for gas flowing in microchannels: a review, Heat and Mass Transfer, Vol. 38, 2002, pp. 359-367.

[72] Hao P.F, Ding Y., Yao Z., He F., and Zhu K. Size effect on gas flow in micro nozzles, Journal of Micromechanics and Microengineering, Vol. 15, 2005, pp. 2069-2073.

[73] Zhu Y., and Jiang P., Experimental and numerical investigation of the effect of shock wave characteristics on the ejector performance, International Journal of Refrigeration, Vol. 40, 2014, pp. 31-42.

[74] Hall P., Taylor-Gortler vortices in fully developed or boundary-layer flows: linear theory, Journal of Fluid Mechanics, Vol. 124, 1982, pp. 475-494.

[75] Saric W.S.m, Gortler Vortices, Annual Reviews Fluid Mechanics, Vol. 26, 1994, pp 379-409.

[76] Owston R., Magi V., and Abraham J., Fuel-Air Mixing Characteristics of DI Hydrogen Jets, SAE Int. J. Engines, 2009, pp. 693-712. 


\section{NOMENCLATURE}

AUSM Advection Upstream Splitting Method

$C_{p} \quad$ Specific heat

$C_{s} \quad$ Sutherland's constant

$\mathrm{CH}_{4} \quad$ Methane

$D \quad$ Nozzle exit diameter

$D_{i} \quad$ Diffusion coefficient

DES Detached Eddy Simulation

DNS Direct Numerical Simulation

DI Direct Injection

$\mathbf{f}_{f} \quad$ Inviscid fluxes

FV Finite Volume

$\mathbf{g}_{f} \quad$ Viscous fluxes

G Gortler number

$\mathrm{H}_{2} \quad$ Hydrogen

$H_{\text {disk }} \quad$ Mach disk height

I Identity matrix

IC Internal Combustion

ILES Implicit Large Eddy Simulation

$k \quad$ Turbulent kinetic energy

Kn Knudsen number

$l_{\text {sub }} \quad$ Subsonic length after the Mach disk

LDA Laser Doppler Anemometry

LES Large Eddy Simulation

$M_{i} \quad$ Molecular weight

Ma Mach number

$M a_{1} \quad$ Nozzle exit Mach number

NPR Nozzle Pressure Ratio

$P \quad$ Fluid pressure

$P_{0} \quad$ Stagnation pressure

$P_{1} \quad$ Nozzle exit pressure

$P_{\infty} \quad$ Ambient pressure

PFI Port Fuel Injection

PLIF Planar laser-induced fluorescence

$R \quad$ Gas constant

$r \quad$ Radius of the shock cell curvature

RANS Reynolds Averaged Navier-Stokes

Re Reynolds Number 


$\begin{array}{ll}\mathbf{S} & \text { Strain tensor } \\ t & \text { Simulation time } \\ t_{0} & \text { Integral time scale } \\ \mathrm{T} & \text { Transpose sign } \\ T & \text { Temperature } \\ T_{0} & \text { Stagnation temperature } \\ T_{1} & \text { Nozzle exit temperature } \\ T_{s} & \text { Reference temperature in Sutherland's law } \\ \mathbf{T} & \text { Viscous stress tensor } \\ U & \text { Velocity magnitude } \\ U_{1} & \text { Nozzle exit velocity } \\ U_{s} & \text { Velocity scale in Gortler number } \\ \mathbf{V} & \text { Velocity vector } \\ V & \text { Computational cell volume } \\ V_{\text {jet }} & \text { Under-expanded jet volume } \\ W_{\text {disk }} & \text { Mach disk width } \\ \mathrm{WENO}_{\mathrm{Z}} \text { Weighted Essentially Non-Oscillatory } \\ X & \text { Mole fraction } \\ Y_{i} & \text { Mixture species } \\ \mathrm{Z} & \text { Axial distance from the nozzle exit } \\ \mathrm{Z}_{\mathrm{t}} & \text { Jet tip penetration }\end{array}$

\section{Special characters}

$\beta \quad$ Reflected shock angle

$\gamma \quad$ Ratio of specific heats

$\varepsilon \quad$ Turbulent dissipation rate

$\Delta \quad$ Length scale (LES grid filter)

$\delta \quad$ Shear layer thickness in under-expanded jets

$\boldsymbol{\delta} \quad$ Boundary layer thickness

$\theta \quad$ Thickness of incoming boundary layer

$\mu \quad$ Dynamic viscosity

$\mu_{\mathrm{s}} \quad$ Reference viscosity in Sutherland's law

$\mu_{\mathrm{t}} \quad$ Turbulent viscosity

$v \quad$ Kinematic viscosity

$\rho \quad$ Density

$\rho_{1} \quad$ Nozzle exit density

$\sigma \quad$ Molecular Schmidt number

$\sigma_{12}$ Collision diameter 
$\omega$ Specific dissipation rate

$\mathbf{\Omega}$ Molecular property in Chapman-Enskong formulation

$\nabla \quad$ Gradient operator 


\section{LIST OF TABLES}

Table 1. Sutherland's constants for different gases.

Table 2. Parameters of current study in comparison to previous numerical studies of under-expanded jets.

Table 3. Characteristics of the under-expanded jets under study.

\section{LIST OF FIGURES}

Figure 1. Schematic of the near-nozzle structure of under-expanded jets (based on Crist et al. [23]).

Figure 2. Left: Grid and domain dimensions. Right-Top: Close-up view of refined areas. Right-Bottom: Nozzle profile and dimensions based on [56].

Figure 3. Near-nozzle shock structure. Left: Schlieren [56]. Right: Current LES study.

Figure 4. (a), (b): Comparison between the time-averaged density gradient $(|\nabla \rho|)$ of the current LES study (right) and RMS Schlieren image of [56] (right). (c) Instantaneous LES snapshot of $|\nabla \rho|$.

Figure 5. Scaled jet tip penetration versus normalized time.

Figure 6. Scaled jet volumetric growth versus normalized time.

Figure 7. Development of under-expanded jet and near-nozzle shock structure. (a): Methane NPR=8.5, (b): Hydrogen NPR=8.5, (c): Hydrogen NPR=10, (d): Hydrogen NPR=30.

Figure 8. Development of the axial Mach number in the hydrogen jet with NPR=10.

Figure 9. Methane and hydrogen jets with NPR=8.5. Left: Turbulent and mixing structure. Right: Close-up view of the near-nozzle shock structure.

Figure 10. Mach disk height $\left(\boldsymbol{H}_{\text {disk }}\right)$ as a function of NPR. Comparison between the current LES study and available empirical relations.

Figure 11. Contour snapshots of various flow parameters at $t=0.2 \mathrm{~ms}$. (a): Methane NPR=8.5, (b): Hydrogen $\mathrm{NPR}=8.5$, (c): Hydrogen NPR=10, (d): Hydrogen NPR=30.

Figure 12. Centre-line normalized temperature at $t=0.2 \mathrm{~ms}$ (Horizontal lines: $-\cdots-$ normalized ambient temperature based on methane's exit temperature, $-\cdots-$ normalized ambient temperature based on hydrogen's exit temperature).

Figure 13. Centre-line axial Mach number at $t=0.2 \mathrm{~ms}$.

Figure 14. Centre-line absolute pressure at $t=0.2 \mathrm{~ms}$.

Figure 15. Centre-line normalised density at $t=0.2 \mathrm{~ms}$.

Figure 16. Nozzle exit pressure and mass flow of hydrogen jets as a function of NPR.

Figure 17. Jet tip penetration. 
Table 1. Sutherland's constants for different gases.

\begin{tabular}{|c|c|c|c|}
\hline Gas & $\boldsymbol{\mu}_{\boldsymbol{S}}[\mathbf{k g} / \mathbf{m s}]$ & $\boldsymbol{T}_{\boldsymbol{S}}[\mathbf{K}]$ & $\boldsymbol{C}_{\mathbf{S}}[\mathbf{K}]$ \\
\hline Air & $1.827 \times 10^{-5}$ & 291.15 & 120 \\
\hline $\mathrm{H}_{2}$ & $8.76 \times 10^{-6}$ & 293.85 & 72 \\
\hline $\mathrm{CH}_{4}$ & $1.201 \times 10^{-5}$ & 273.15 & 197.8 \\
\hline
\end{tabular}

Table 2. Parameters of current study in comparison to previous numerical studies of under-expanded jets.

\begin{tabular}{|c|c|c|c|c|c|c|c|c|}
\hline Authors & Year & $\begin{array}{l}\text { Flow } \\
\text { Type }\end{array}$ & Gas & NPR & $D[\mathrm{~mm}]$ & Method & Grid Type & $\begin{array}{c}\text { Refined } \\
\text { Area }\end{array}$ \\
\hline $\begin{array}{c}\text { Dauptain et al. } \\
{[49,50]}\end{array}$ & $\begin{array}{c}2010 \& \\
2012\end{array}$ & $\begin{array}{l}\text { Free \& } \\
\text { Impinging } \\
\text { Jets }\end{array}$ & Air & $\sim 4$ & 25.4 & $\begin{array}{c}\text { LES } \\
\text { (Smagorinsky) }\end{array}$ & $\begin{array}{l}\text { Unstructured } \\
\text { Tetrahedral }\end{array}$ & $D / 35$ \\
\hline $\begin{array}{c}\text { Khaksarfard et } \\
\text { al. } \\
{[59]}\end{array}$ & 2010 & Free Jet & $\mathrm{H}_{2}$ & 100-700 & 5.0 & $\begin{array}{l}\text { Inviscid Euler } \\
\text { Equations }\end{array}$ & $\begin{array}{l}\text { Unstructured } \\
\text { Tetrahedral }\end{array}$ & - \\
\hline $\begin{array}{c}\text { Gorlé et al. } \\
{[57,58]}\end{array}$ & 2011 & $\begin{array}{c}\text { Free \& } \\
\text { Cross } \\
\text { Flow Jets }\end{array}$ & $\mathrm{H}_{2}$ & 30 & 2.0 & $\begin{array}{l}\text { RANS }(k-\omega) \\
\text { \& LES } \\
\text { (WENO) }\end{array}$ & $\begin{array}{l}\text { Unstructured } \\
\text { Hexahedral }\end{array}$ & $\begin{array}{c}D / 100 \\
\text { Stretched to } \\
D / 25\end{array}$ \\
\hline $\begin{array}{c}\text { Velikorodny \& } \\
\text { Kudriakov } \\
{[28]}\end{array}$ & 2012 & Free Jet & He \& Air & 30 & 1.0 & $\begin{array}{l}\text { Monotonically } \\
\text { Integrated } \\
\text { LES }\end{array}$ & $\begin{array}{l}\text { Structured } \\
\text { Hexahedral }\end{array}$ & $D / 36$ \\
\hline $\begin{array}{c}\text { Chin et al. } \\
\text { [46] }\end{array}$ & 2013 & $\begin{array}{l}\text { Free \& } \\
\text { Impinging } \\
\text { Jets }\end{array}$ & Air & $\begin{array}{l}\sim 1.95 \\
\sim 3.6\end{array}$ & 4.0 & $\begin{array}{c}\text { RANS } \\
(k-\varepsilon, k-\omega-S S T)\end{array}$ & $\begin{array}{l}\text { Structured } \\
\text { Hexahedral }\end{array}$ & $\begin{array}{c}\text { Radial: } \\
D / 200 \\
\text { Stretched to } \\
D / 2, \text { Axial: } \\
D / 20 \text { to } \\
D / 2.5\end{array}$ \\
\hline $\begin{array}{c}\text { Vuorinen et al. } \\
\text { [51] }\end{array}$ & 2013 & Free Jet & $\begin{array}{l}\text { Passive } \\
\text { Scalar } \\
\left(\mathrm{N}_{2}\right)\end{array}$ & $\begin{array}{l}4.5,5.5 \\
6.5,7.5 \\
\quad 8.5\end{array}$ & 1.4 & $\begin{array}{l}\text { Implicit LES } \\
\text { with Bulk } \\
\text { Viscosity }\end{array}$ & $\begin{array}{l}\text { Structured } \\
\text { Hexahedral }\end{array}$ & $\begin{array}{l}D / 70 \text { Radia } \\
\& D / 35 \\
\text { Axial }\end{array}$ \\
\hline $\begin{array}{c}\text { Bonelli et al. } \\
\text { [60] }\end{array}$ & 2013 & Free Jet & $\mathrm{H}_{2}$ & 15 & 0.3 & $\begin{array}{l}\text { RANS }(k-\varepsilon) \\
\text { with TVD }\end{array}$ & $\begin{array}{c}\text { Structured } \\
\text { Hexahedral }\end{array}$ & $D / 30$ \\
\hline Current Study & 2014 & Free Jet & $\begin{array}{l}\mathrm{H}_{2} \& \\
\mathrm{CH}_{4}\end{array}$ & $\begin{array}{l}8.5,10 \\
30,70\end{array}$ & 1.5 & $\begin{array}{l}\text { LES (WALE) } \\
\text { with AUSM }\end{array}$ & $\begin{array}{l}\text { Unstructured } \\
\text { Hexahedral }\end{array}$ & $\begin{array}{c}D / 50 \text { All } \\
\text { Directions }\end{array}$ \\
\hline
\end{tabular}


Table 3. Characteristics of the under-expanded jets under study.

\begin{tabular}{|c|c|c|c|c|c|c|c|}
\hline Gas & NPR & $\begin{array}{c}\text { Mach Disk } \\
\text { Height } \\
{[\mathbf{m m}]}\end{array}$ & $\begin{array}{c}\text { Mach Disk } \\
\text { Width } \\
{[\mathbf{m m}]}\end{array}$ & $\begin{array}{c}\text { Reflected } \\
\text { Shock } \\
\text { Angle }[\mathbf{d e g}]\end{array}$ & $\begin{array}{c}\text { Shear } \\
\text { Layer } \\
\text { Thickness } \\
{[\mathbf{m m}]}\end{array}$ & $\begin{array}{c}\text { Subsonic } \\
\text { Length } \\
(\mathbf{M a}<\mathbf{0 . 9}) \\
{[\mathbf{m m}]}\end{array}$ & $\begin{array}{c}\text { Acceleration } \\
\text { Length } \\
{[\mathbf{m m}]}\end{array}$ \\
\hline $\mathrm{CH}_{4}$ & 8.5 & 2.85 & 1.218 & $\sim 28.5$ & $\sim 0.7$ & 4.05 & 1.67 \\
\hline $\mathrm{H}_{2}$ & 8.5 & 2.78 & 1.091 & $\sim 28.5$ & $\sim 0.327$ & 2.03 & 2.03 \\
\hline $\mathrm{H}_{2}$ & 10 & 3.09 & 1.34 & $\sim 28.0$ & $\sim 0.318$ & 4.035 & 1.87 \\
\hline $\mathrm{H}_{2}$ & 30 & 5.65 & 3.37 & $\sim 28.0$ & $\sim 0.266$ & 5.75 & 5.75 \\
\hline $\mathrm{H}_{2}$ & 70 & 8.72 & NA & $\sim 28.0$ & NA & No Cell & No Cell \\
\hline
\end{tabular}




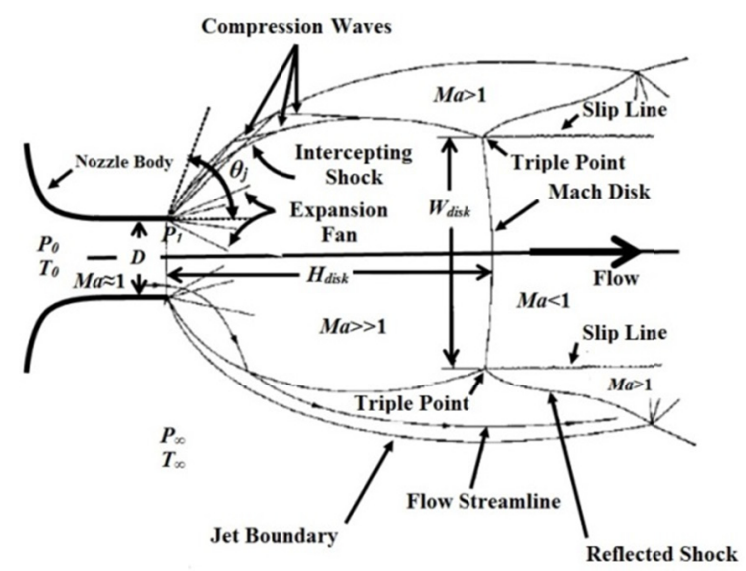

Figure 1. Schematic of the near-nozzle structure of under-expanded jets (based on Crist et al. [23]).
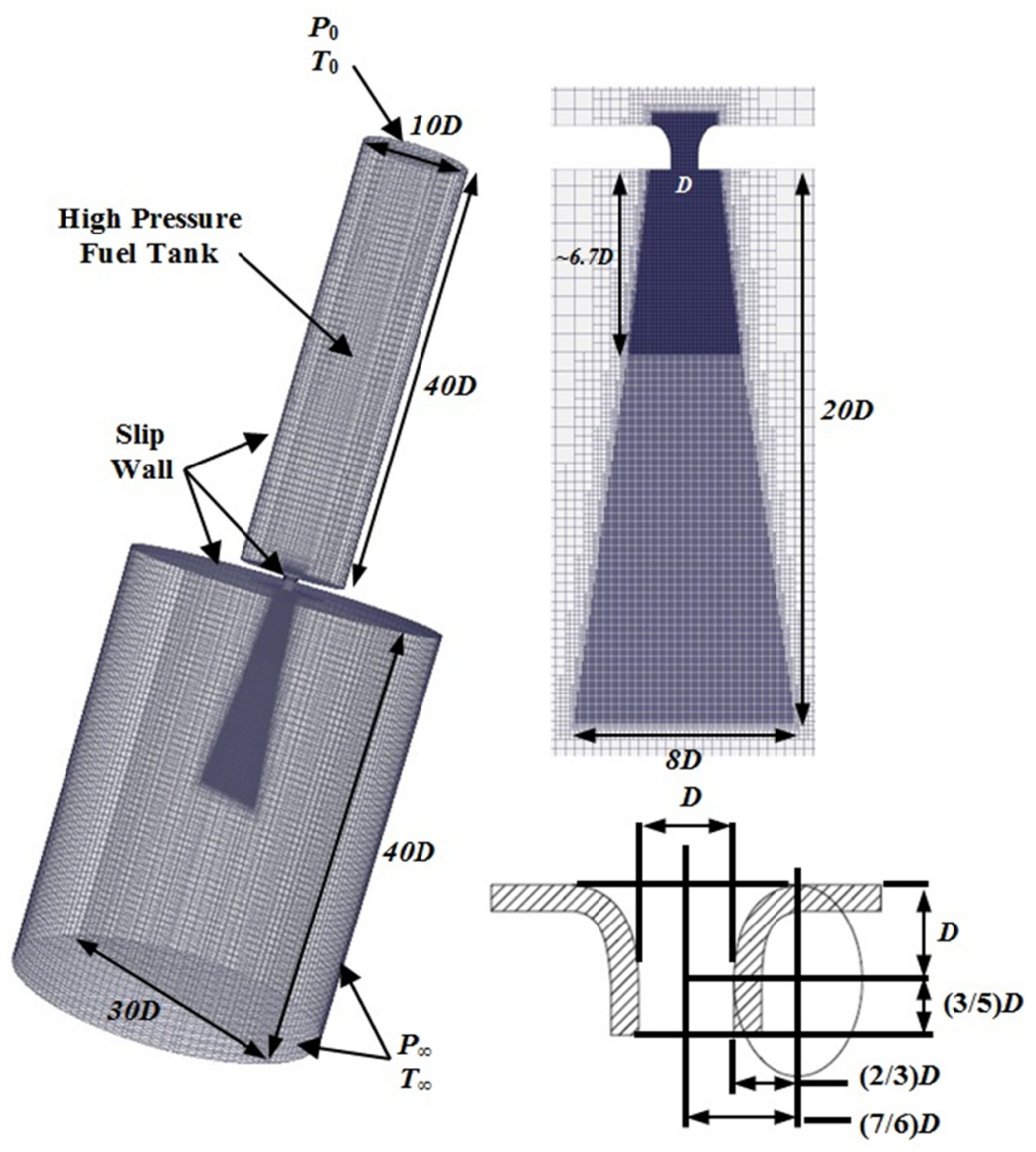

Figure 2. Left: Grid and domain dimensions. Right-Top: Close-up view of refined areas. Right-Bottom: Nozzle profile and dimensions based on [56]. 


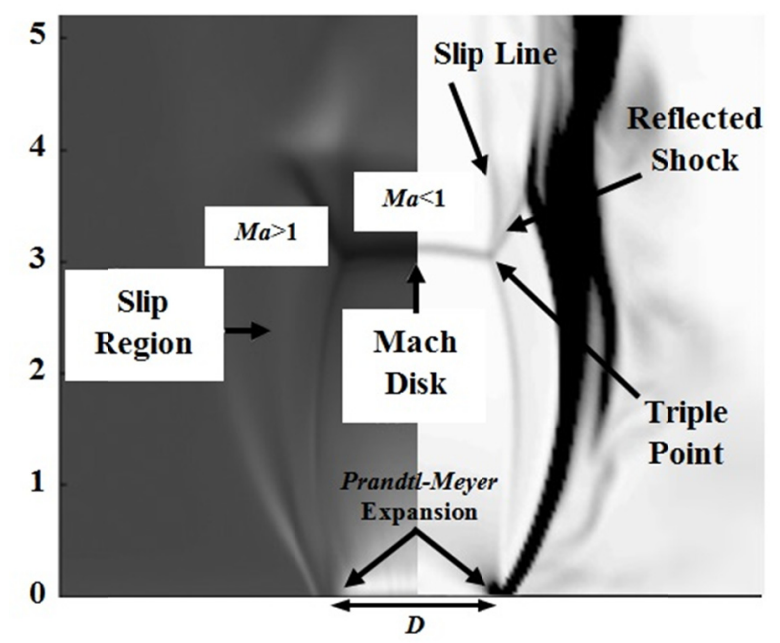

Figure 3. Near-nozzle shock structure. Left: Schlieren [56]. Right: Current LES study.
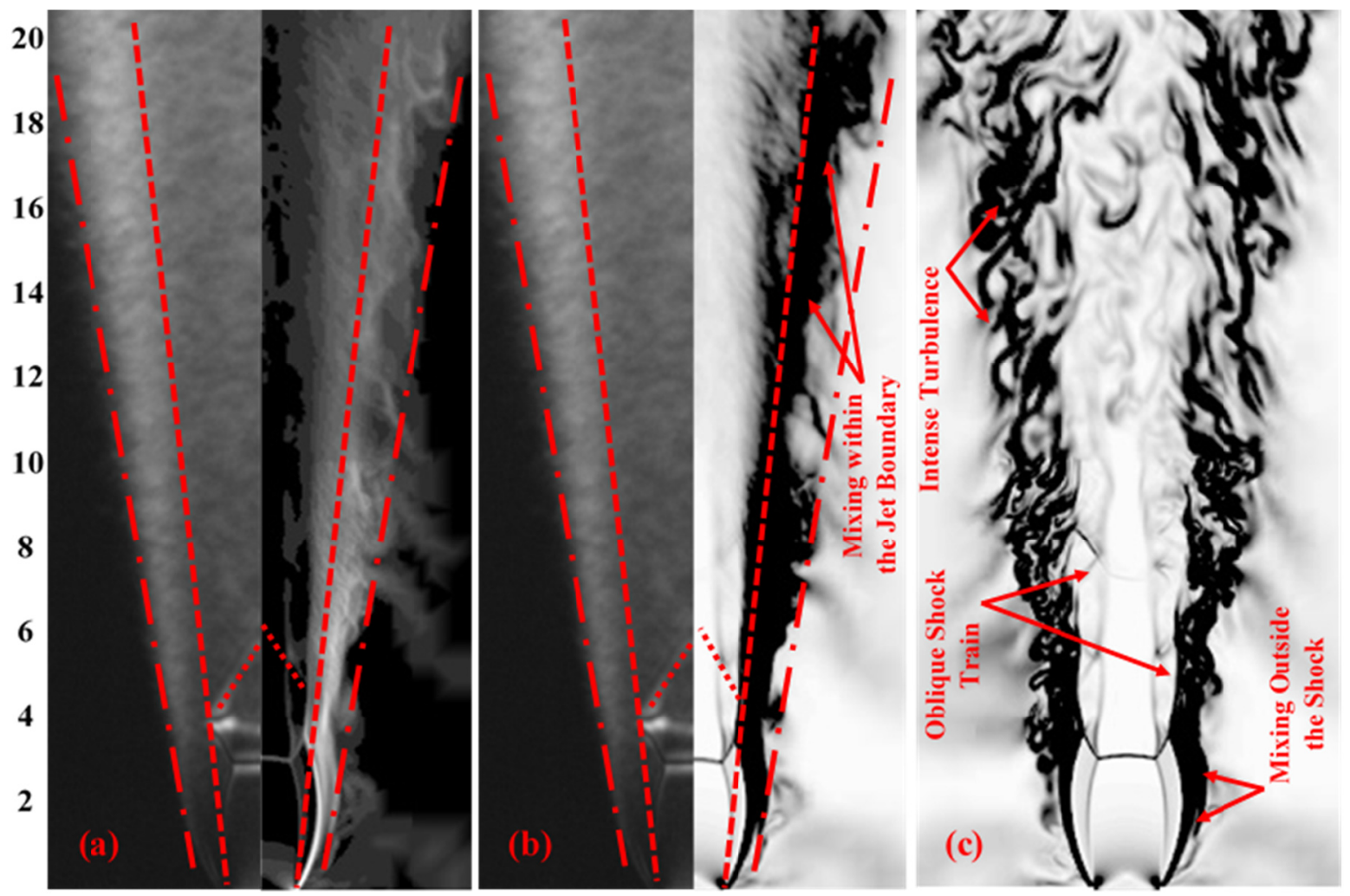

Figure 4. (a), (b): Comparison between the time-averaged density gradient $(|\nabla \rho|)$ of the current LES study (right) and RMS Schlieren image of [56] (right). (c) Instantaneous LES snapshot of $|\nabla \rho|$. 


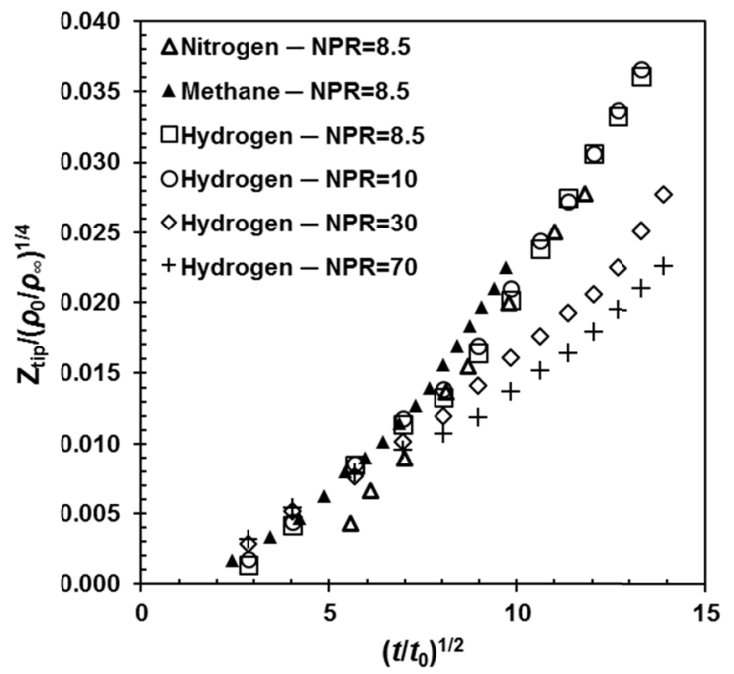

Figure 5. Scaled jet tip penetration versus normalized time.

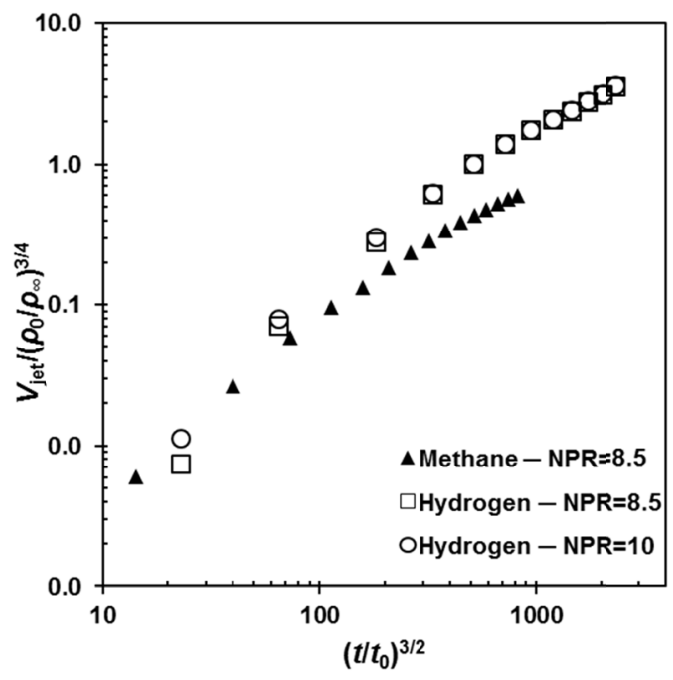

Figure 6. Scaled jet volumetric growth versus normalized time. 


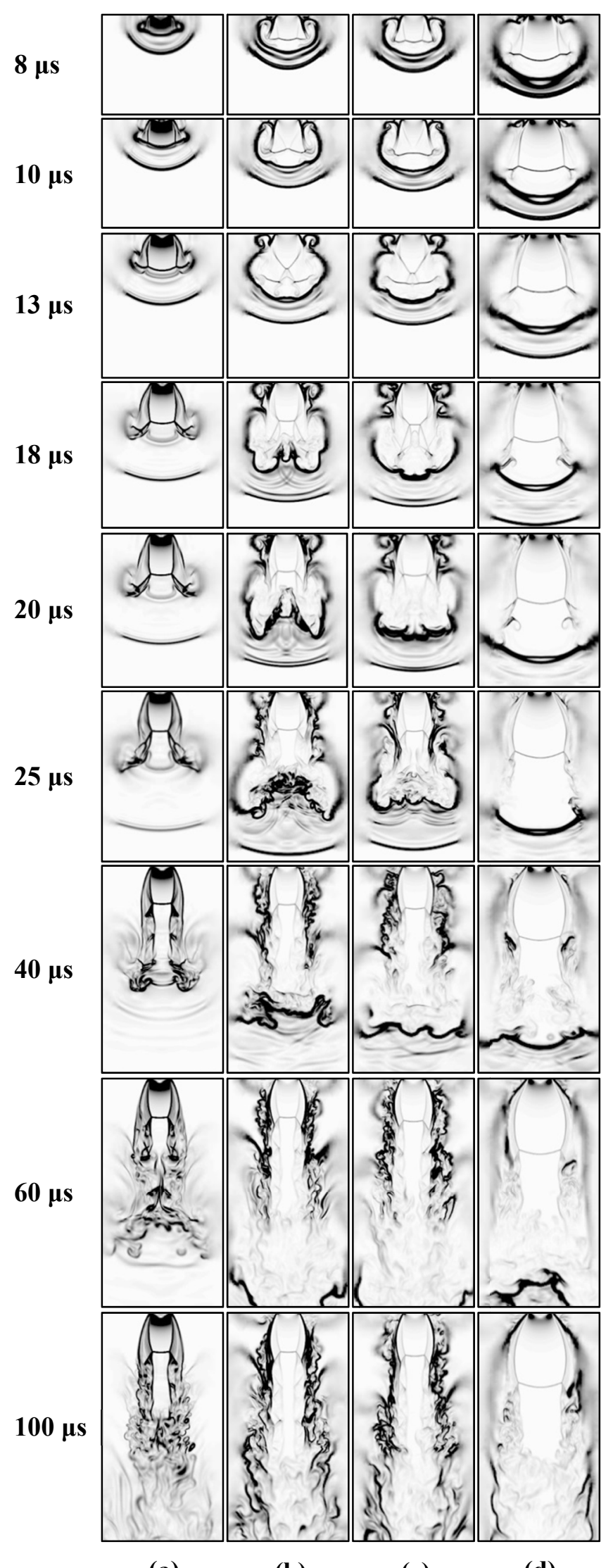

$\begin{array}{llll}\text { (a) } & \text { (b) } & \text { (c) }\end{array}$

Figure 7. Development of under-expanded jet and near-nozzle shock structure. (a): Methane NPR=8.5, (b): Hydrogen NPR=8.5, (c): Hydrogen NPR=10, (d): Hydrogen NPR=30. 


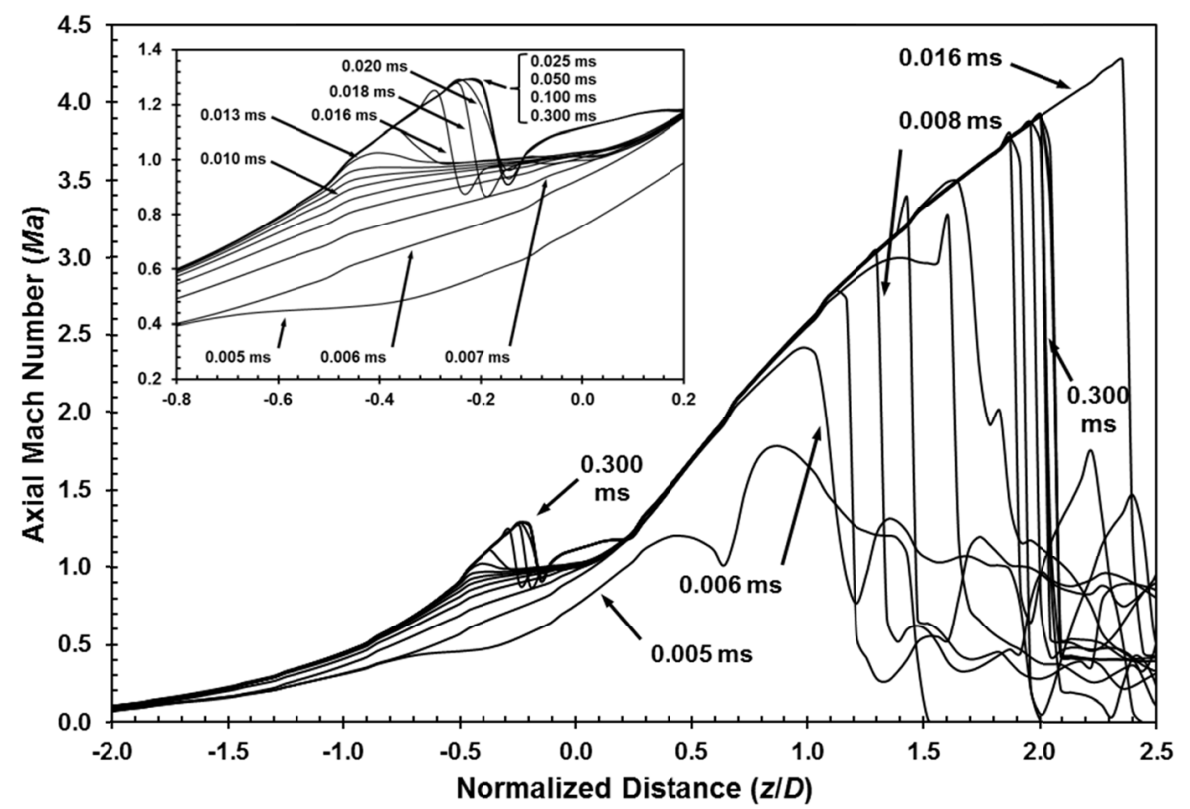

Figure 8. Development of the axial Mach number in the hydrogen jet with NPR=10.
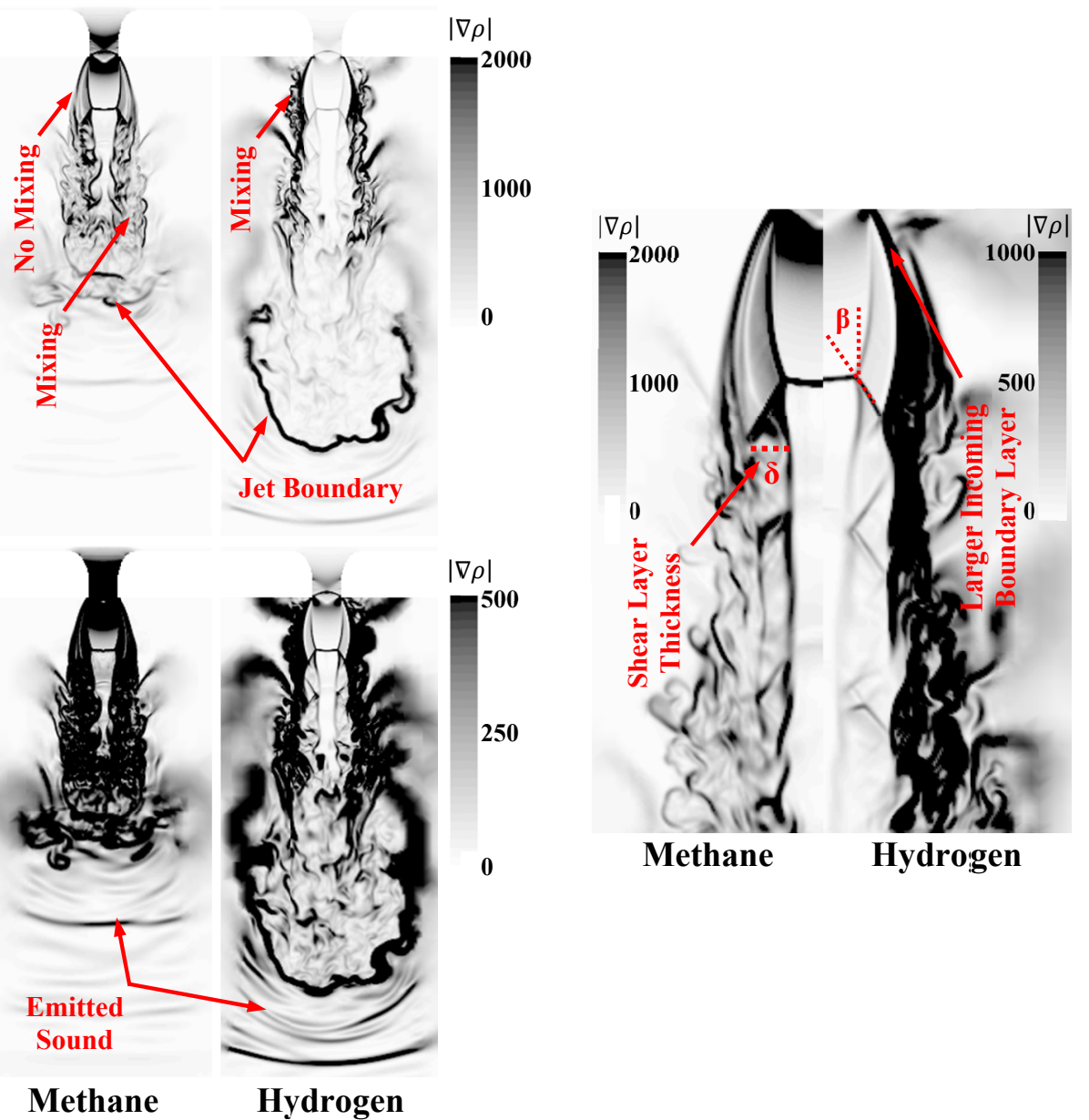

Figure 9. Methane and hydrogen jets with NPR=8.5. Left: Turbulent and mixing structure. Right: Close-up view of the near-nozzle shock structure. 


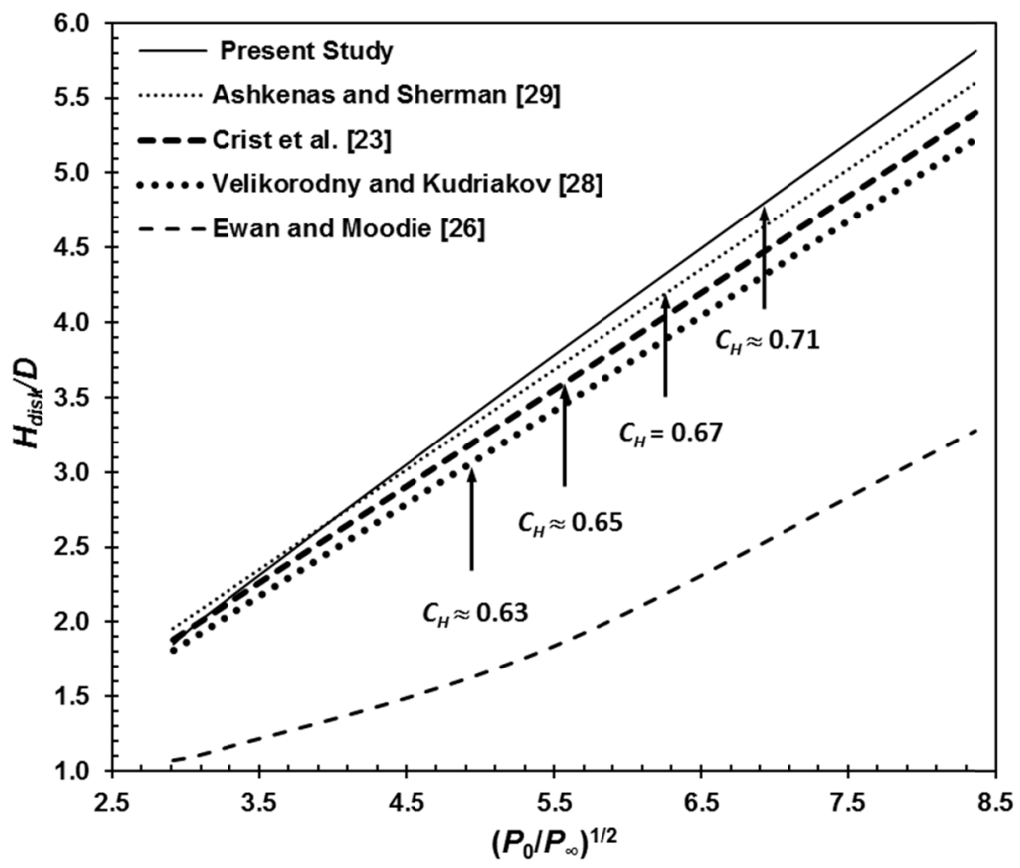

Figure 10. Mach disk height $\left(H_{\text {disk }}\right)$ as a function of NPR. Comparison between the current LES study and available empirical relations. 

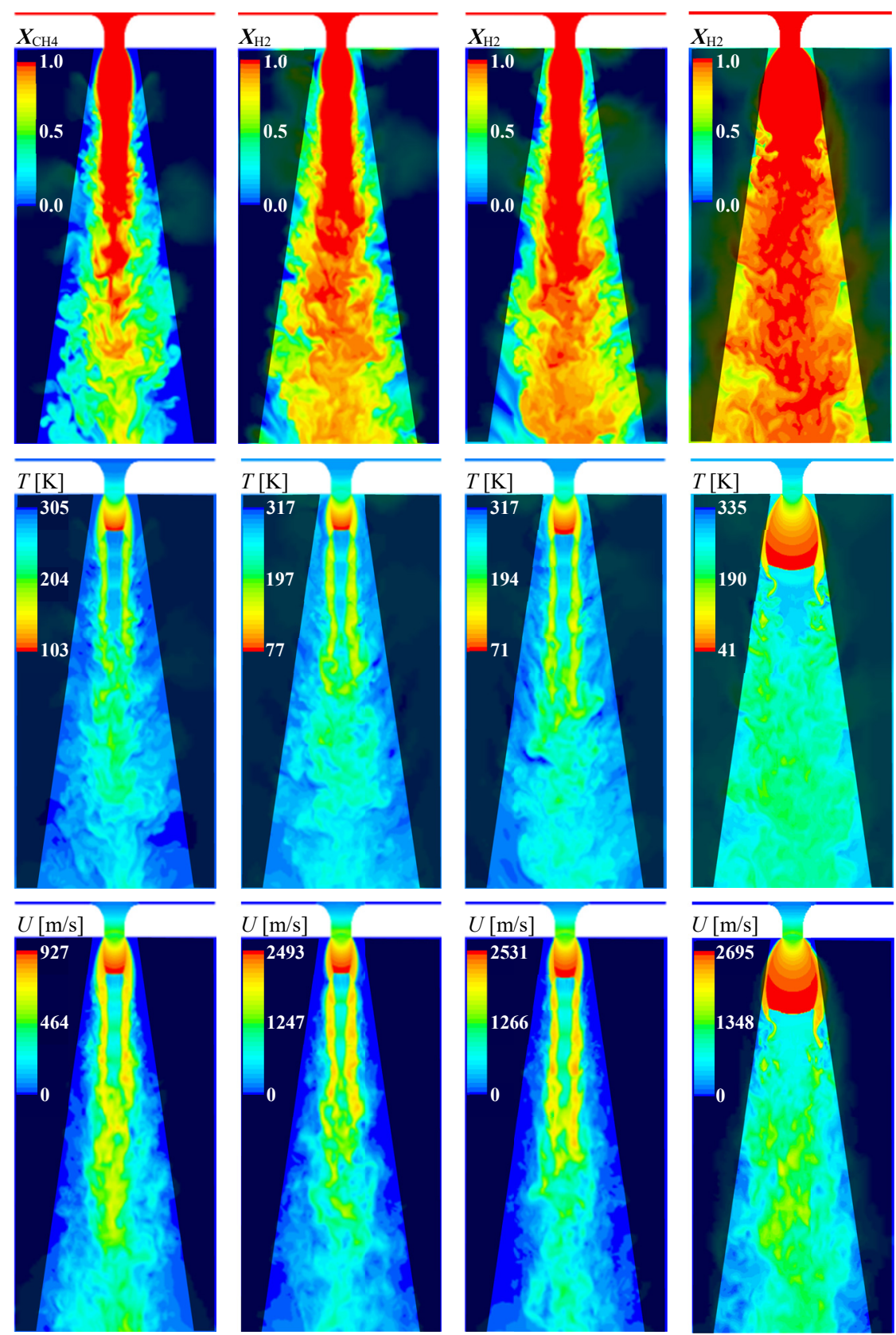

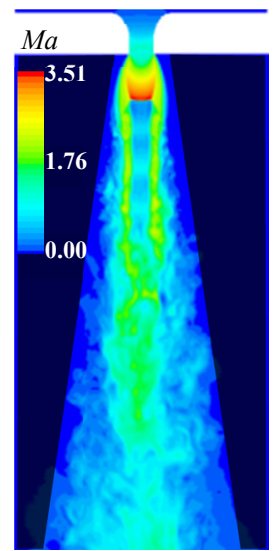

(a)

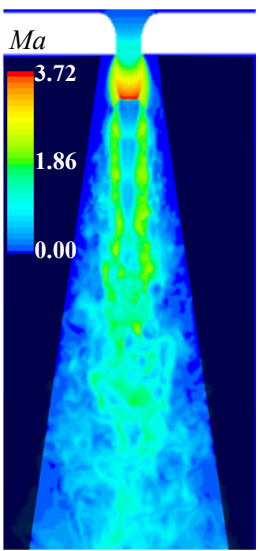

(b)

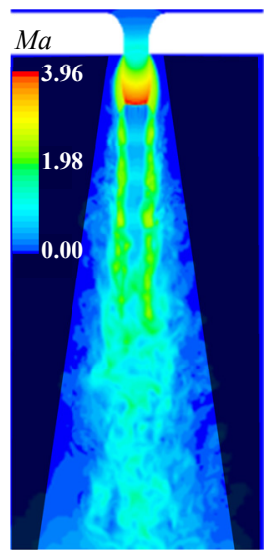

(c)

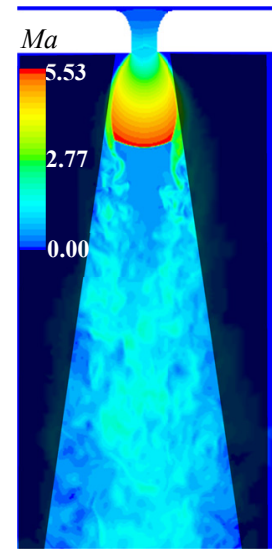

(d)

Figure 11. Contour snapshots of various flow parameters at $t=0.2 \mathrm{~ms}$. (a): Methane NPR=8.5, (b): Hydrogen $\mathrm{NPR}=8.5$, (c): Hydrogen NPR=10, (d): Hydrogen NPR=30. 


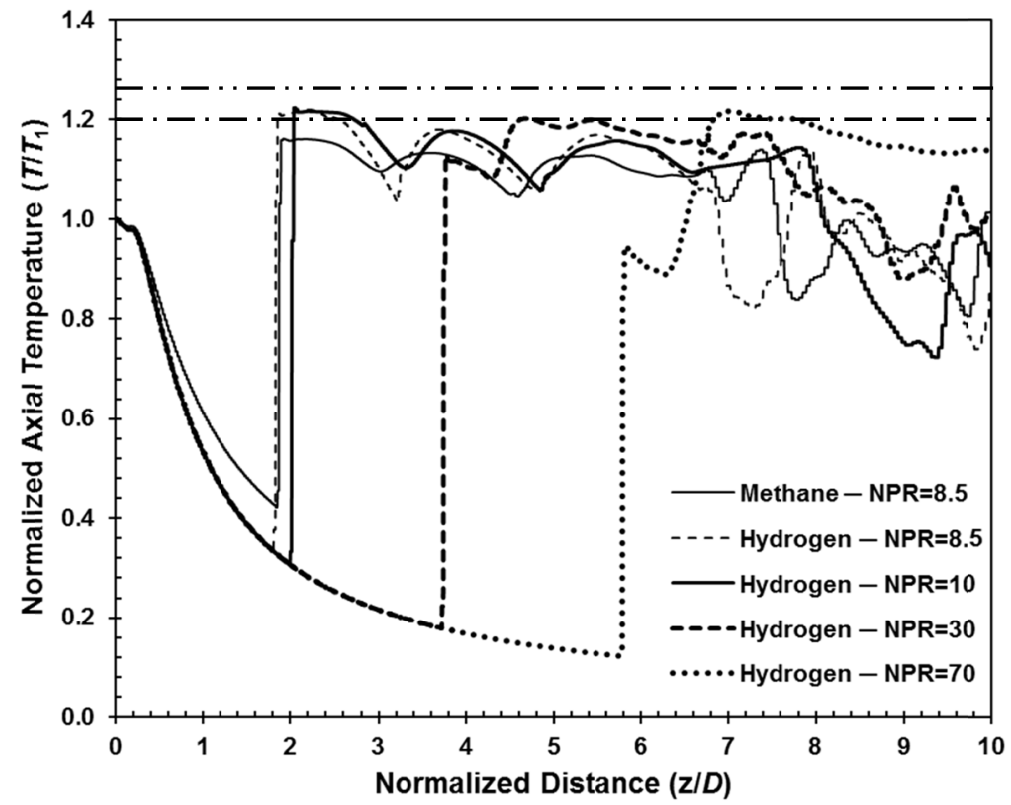

Figure 12. Centre-line normalized temperature at $t=0.2 \mathrm{~ms}$ (Horizontal lines: $-\cdot-$ normalized ambient temperature based on methane's exit temperature, $-\cdots$ - normalized ambient temperature based on hydrogen's exit temperature).

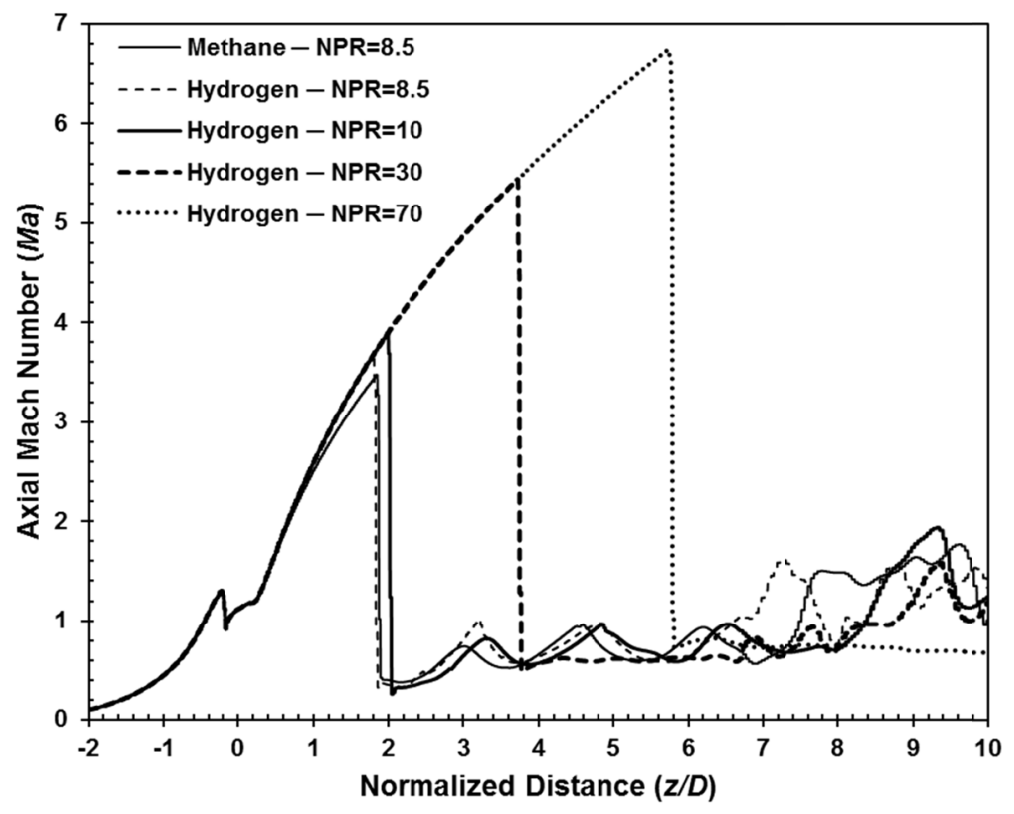

Figure 13. Centre-line axial Mach number at $t=0.2 \mathrm{~ms}$. 


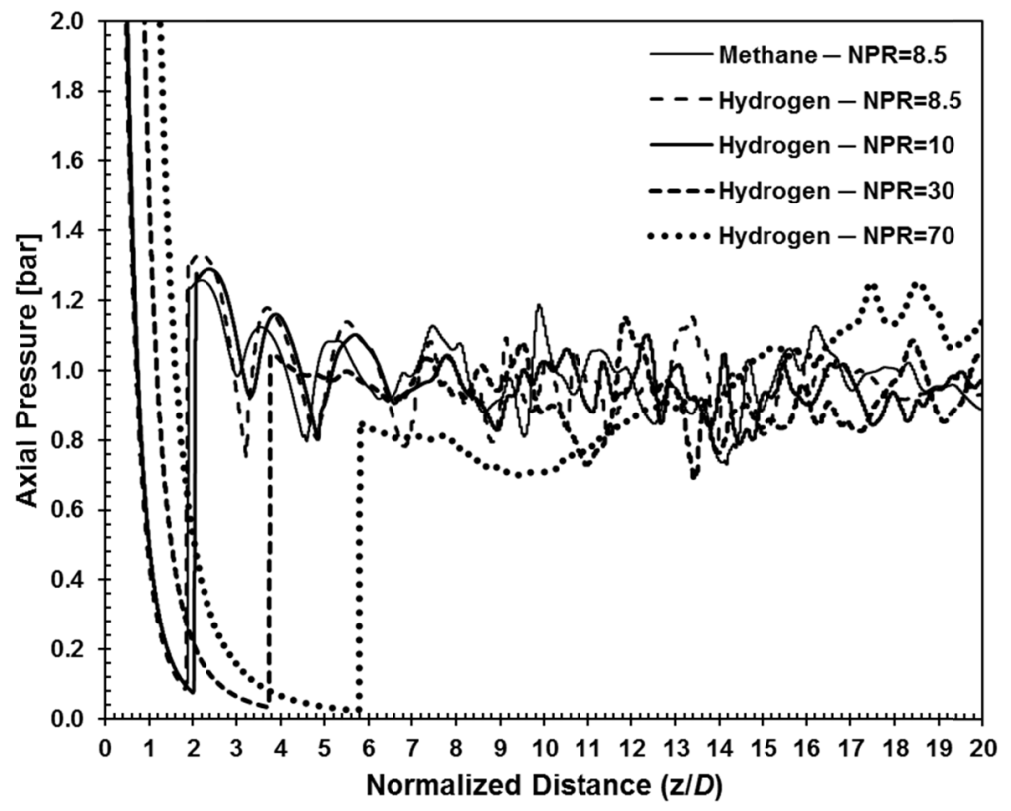

Figure 14. Centre-line absolute pressure at $t=0.2 \mathrm{~ms}$.

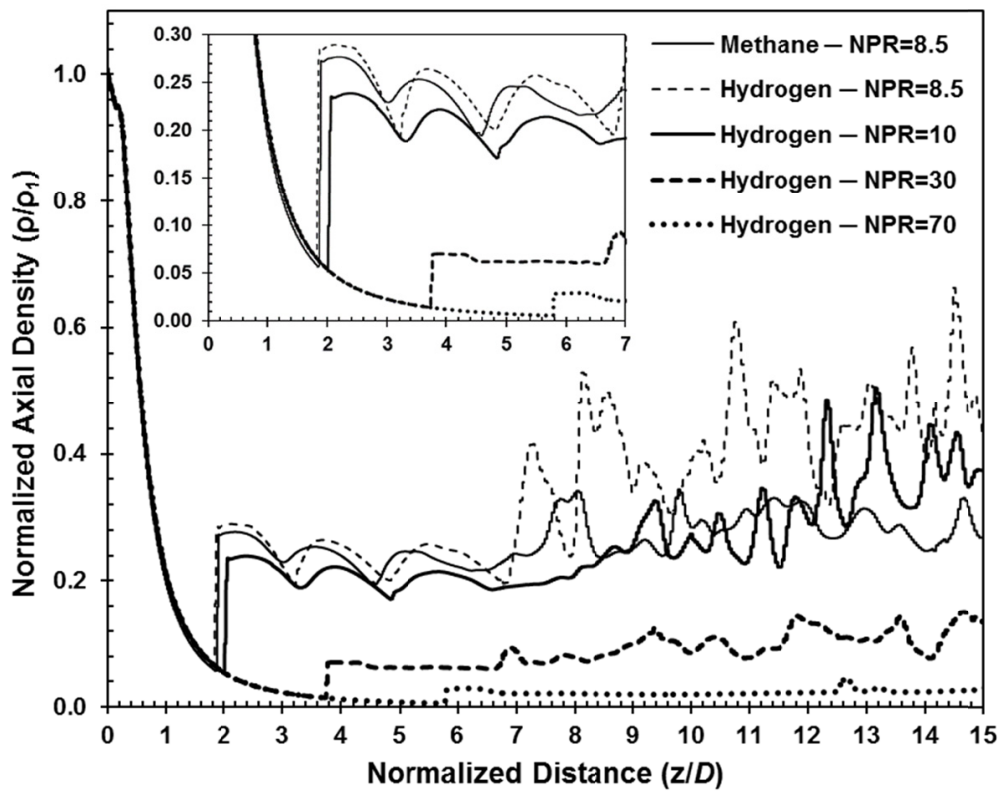

Figure 15 . Centre-line normalised density at $t=0.2 \mathrm{~ms}$. 


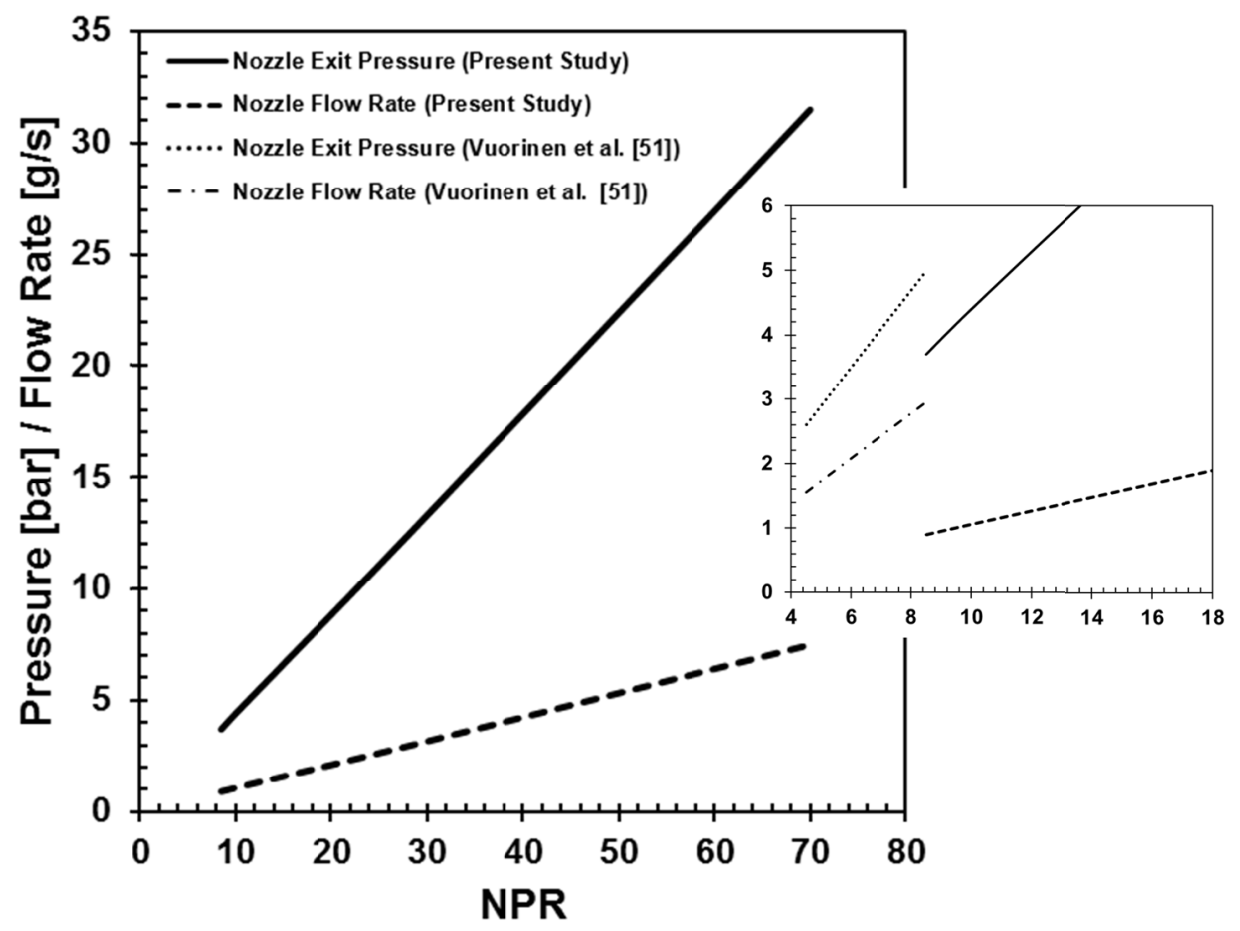

Figure 16. Nozzle exit pressure and mass flow of hydrogen jets as a function of NPR.

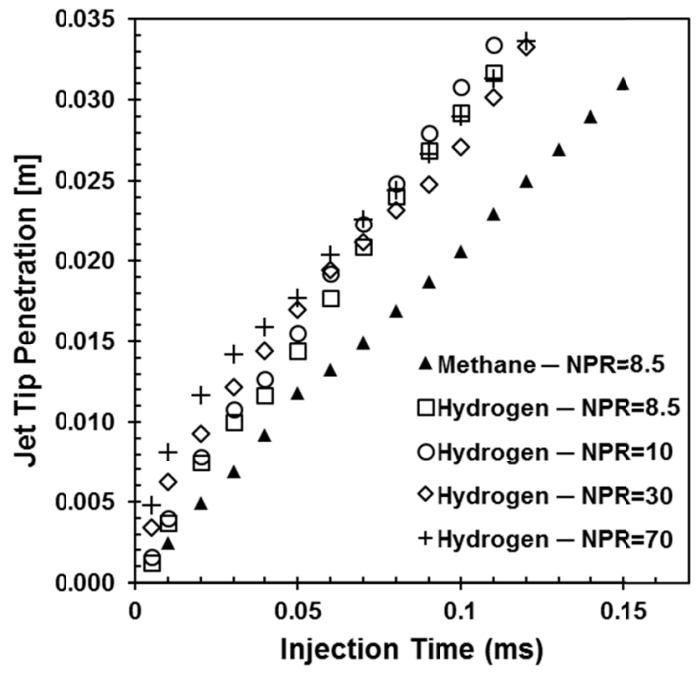

Figure 17. Jet tip penetration. 